\title{
A New Survey of Multiring Impact Basins on Mars
}

\author{
RICHARD A. SCHULTZ ${ }^{1}$ AND HERBERT V. FREY
}

Geadynamics Branch, NASA Goddard Space Flight Center, Greenbelt, Maryland

\begin{abstract}
Multiring impact basins have profoundly influenced the geologic evolution of Mars. We compile and summarize the evidence for Martian impact basins and suggest eight new examples. Multiring basins on Mars define three morphologic subclasses with increasing basin size. Basins having diameters $300<D<1850 \mathrm{~km}$ are morphologically comparable to the classic lunar Orientale basin. Argyre type basins $(1850<D<3600 \mathrm{~km})$ are characterized by a rugged annulus and concentric grabens. The largest, Chryse type basins $(D>3600 \mathrm{~km})$ have exiremely shallow topographic profiles and numerous concentric structures expressed as scarps, massifs, and channels. Radial and concentric structures analogous to those associated with Orientale are not apparent for basins of Argyre size or larger. These variations in basin morphology and structure may be associated with mechanical interactions between basin-forming impacts, relatively thin, weak lithosphere, and, for the largest impacts, spherical target geometry. Multiring basins are recognized on all parts of Mars, including Tharsis, Elysium, and the northem lowlands. Much of the subsequent resurfacing of cratered terrain such as Lunae Planum ridged plains is associated spatially with multiring basins. Nucleation of long-lived volcanic complexes in Tharsis and Elysium was probably aided by early impact basins. The planetary terrain dichotomy was probably established during the period of heavy meteoritic bombardment, and subsequent processes in the northem plains region were not sufficiently vigorous to destroy or completely obscure the underlying multiring basin fabric. The revised population of multiring basins is consistent with the size frequency distribution of craters $<500 \mathrm{~km}$ in diameter on Mars. Basins having diameters $\sim 500<D<1850 \mathrm{~km}$ are characterized by a cumulative frequency slope of $-0.75 \pm 0.16$, whereas the larger basins define a slope of $-1.7 \pm 0.45$. This change in slope occurs over the same diameter range as the significant change from Orientale type basin morphology at smaller diameters to Argyre and Chryse type basin morphology. The population of craters and basins on Mars confirms that the relative crater densities on the terrestrial planets due to heavy bombardment are comparable, perhaps suggesting a common source for the impacting objects.
\end{abstract}

\section{INTRODUCTION}

The surface of Mars preserves evidence of multiring impact basins that formed early in the planet's history. On many planets these structures define the fundamental tectonic framework upon which subsequent geologic and geophysical processes are superimposed. For example, most volcanic and tectonic activity on the Moon was localized by preexisting impact basins [e.g., Solomon and Head, 1980]. Control of volcanism, tectonics, erosion, and perhaps volatile dynamics [e.g., Carr, 1989] on Mars by multiring basins can be discerned in many areas [Schultz et al., 1982] even though endogenic processes were quite vigorous over the planet's history. On the other hand, the family of impacting objects that produced these basins is probably related to planetary accretion [Wetherill, 1977, 1981] and size-frequency characteristics of impactor populations can be estimated given an accurate inventory of impact craters and basins [e.g., Strom, 1987]. Thus the record of multiring basins on Mars provides a fundamental link between the planet's accretion and its later development.

In this paper we compile and summarize available data on Martian multiring impact basins having diameters larger than 500 $\mathrm{km}$ and present evidence suggesting several new ones. These results complement earlier surveys of large Martian craters and basins by Wilhelms [1973], Malin [1976], Wood and Head

\footnotetext{
${ }^{1}$ Now at Mackay School of Mines, University of Nevada-Reno.
}

This paper is not subject to U.S. copyright. Published in 1990 by the American Geophysical Union.

Paper number 90JB00910.
[1976], and Schultz et al. [1982]. Many studies assume that the lunar Orientale basin [Head, 1974] is an appropriate template for all multiring basins on any planet or satellite [e.g., Moore et al., 1974; McCauley, 1977; Wilhelms, 1987; cf. Schultz, 1979; Hodges, 1980; Croft, 1981]. This view arose because Orientale is the youngest and best preserved basin on the Moon and because the structure of many basins mimics that of Orientale. Other work has shown, however, that a planet or satellite's near-surface rheology and lithospheric thickness can enhance or impede the formation of concentric basin rings [Melosh and McKinnon, 1978; McKinnon and Melosh, 1980; McKinnon, 1981; Melosh, 1982]. These results suggest that the number of basin rings increases inversely with lithospheric thickness and imply that Orientale multiring structure resulted from a particular set of conditions at the time of impact. Many of the larger basins on Mars, notably Argyre, Hellas, and Chryse, differ morphologically and structurally from Orientale [Wilhelms, 1973; Schultz et al., 1982], and these differences may be related to lithospheric properties at the time of impact. Geologic expression and geophysical processes associated with the largest multiring basins may also be influenced by planetary curvature. For example, theoretical models of large impact structures suggest that formation of concentric rings and postimpact viscous relaxation of basin topography can differ for spherical, rather than planar, impact targets [Melosh, 1982; Thomas and Squyres, 1988]. Thus multiring basins that occurred early in Martian history may differ structurally and morphologically from smaller or younger basins.

\section{PROCEDURE AND RESULTS}

We used the new 1:15,000,000 scale geologic maps of Mars [Scott and Tanaka, 1986; Greeley and Guest, 1987; Tanaka and 
Scott, 1987] and revised global topography [Wu at al., 1986; U.S. Geological Survey, 1989] as base maps. Published center coordinates and ring diameters of previously recognized Martian basins (e.g., compilation by Greeley [1985]) were plotted by computer and superimposed onto the maps. In many cases we had to adjust basin centers or ring diameters or both to achieve a better fit to the revised geologic maps. Given the highly speculative nature of basin recognition, we fully anticipate that more detailed investigation of the larger basins may lead to further revisions.

Identification of concentric ring structures associated with Martian multiring basins can become a difficult exercise, principally because classical Orientale multiring basin structure cannot be recognized for the larger Martian basins such as Argyre (see below). Different investigators may also use different criteria for the selection of basin rings and diameters. Basin "rings" can be inferred by examining the occurrence and distribution of radial and concentric structures, floor-fractured craters [Schultz and Glicken, 1979], massifs, central volcanos and volcanic (?) plains units, topography, and changes in channel geometry [Schultz et al., 1982]. Concentric ring structures are commonly discontinuous so that faults or massifs at given radius may not encircle the entire basin.

We have not tried to infer all possible rings for Martian impact basins. Instead, we choose to present those suggested by previous workers on a common format (e.g., Plate 1, below) and attempt to make some general statements about Martian basins. We find that the morphology, topography, and structure of Martian multiring basins can be approximated very simply by a central depression surrounded by a faulted annulus. The former excavation cavity may be located within the central depression [e.g., Melosh, 1982]. The inner and outer boundaries of many annuli (e.g., Argyre) are marked by discontinuous inward facing scarps and topographic changes, so we choose the outer boundary of the annulus as a working hypothesis for the basin's diameter, or principal ring. Our updated compilation of Martian multiring impact basins is shown in Figure 1, Table 1, and Plates 1 and 2.

Several large impact structures can be postulated in the Tharsis region of Mars (Plate 1b). Frey and Schultz [1989] found that map patterns of Noachian fractured materials and outflow channels between Daedalia Planum and Chryse Planitia could be explained by a large multiring structure located in North Tharsis (Plate $1 b$ and Figure 2; basin 3 in Table 1). At least three rings can be suggested. The innermost ring of North Tharsis is defined by the boundary between volcanic plains units east of Ascraeus Mons and surrounding exposures of old faulted materials (unit Nf, brown in Plate 1). Curved traces of Echus Chasma and the faulted southern margin of Tempe Terra suggest an irregular second ring. Systematic changes in width of older units in Tempe Terra, Noctis Labyrinthus/Claritas Fossae, and Kasai Valles may mark a third ring. The outer, principal ring of North Tharsis basin is inferred from curved, concentric traces of Juventse Chasma/Maja Valles and the boundary between old cratered terrain (unit Npl2; brown in Plate 1) and more interior Lunae Planum ridged plains materials on Tempe Terra and Lunae Planum, widening of Kasai Valles, and the northern margin of Noachian basement material in the southem Claritas Fossae region. Concentric structures at the radial distances of Echus Chasma and Maja Valles can be explained by using a multiring basin paradigm but not by using Tharsis stress models [e.g., Banerdt et al., 1982, 1990; Phillips et al., 1990]. Control of Echus Chasma and Maja Valles by basin ring structures would explain their anomalous trends and locations. Both channels also change trend and width where Chryse basin rings are inferred to occur, suggesting control of southern channel reaches by concentric North Tharsis structure and northem reaches by radial Chryse structure.

Multi-ring structure in Daedalia Planum was suggested independently by Craddock et al. [1990] and Frey and Schultz [1989]. Arcuate escarpments of Noachian materials that formed a
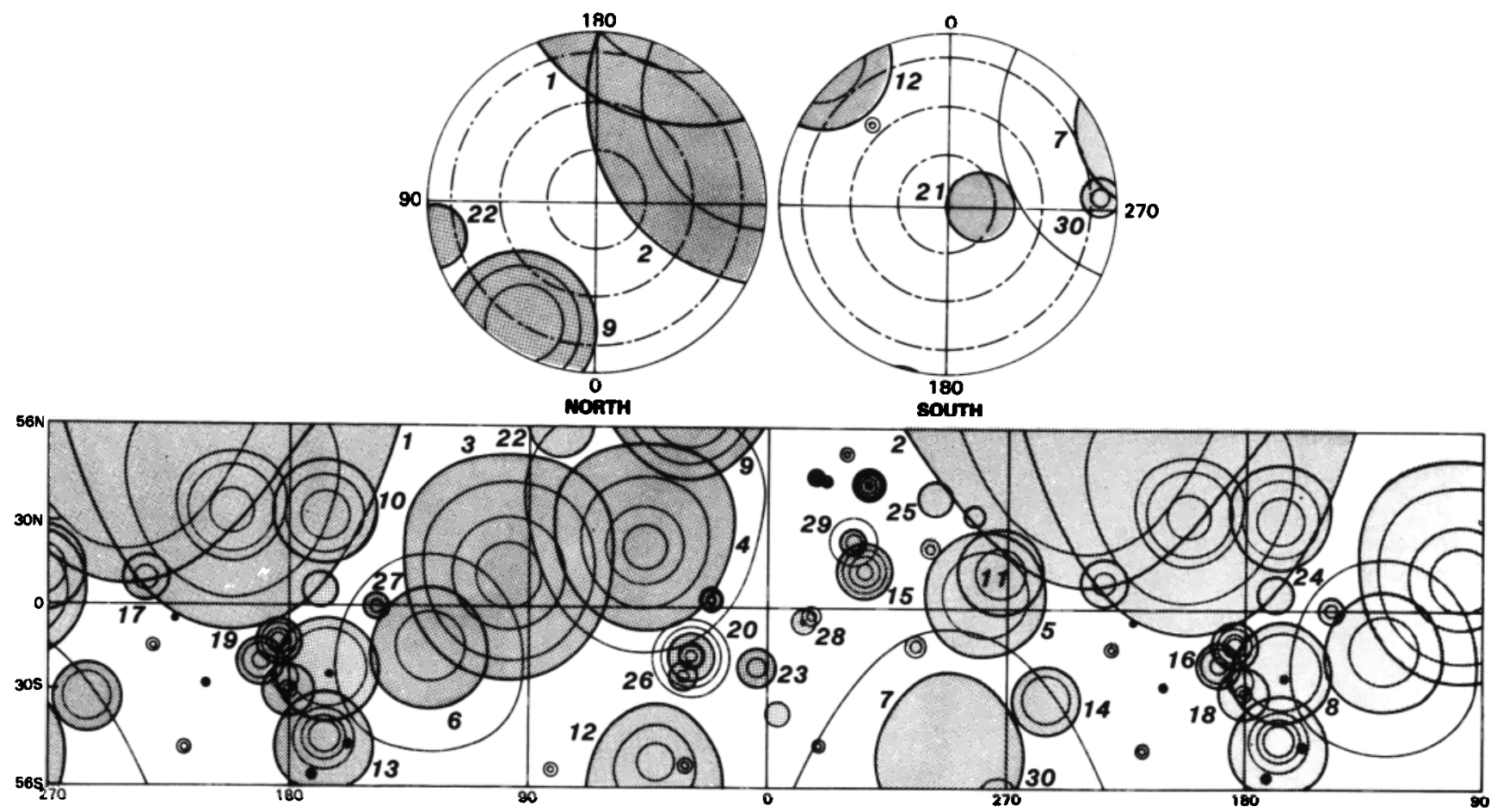

Fig. 1. Multiring basins on Mars. Numbered basins refer to Table 1. Note extended longitude. 
TABLE 1. Multiring Impact Basins on Mars

\begin{tabular}{|c|c|c|c|c|c|}
\hline No. & Name $^{2}$ & Center & $\begin{array}{c}\text { Ring Diameters, } \\
\text { km }\end{array}$ & $D_{p} / R_{M a r s}{ }^{c}$ & Reference $^{d}$ \\
\hline 1 & Elysium & $33^{\circ} \mathrm{N}, 201^{\circ} \mathrm{W}$ & $800 ?, 1540,2000,3600,4970$ & 1.46 & 1 \\
\hline 2 & Utopia & $48^{\circ} \mathrm{N}, 240^{\circ} \mathrm{W}$ & 3300,4715 & 1.39 & (2) \\
\hline 3 & North Tharsis & $11^{\circ} \mathrm{N}, 97.5^{\circ} \mathrm{W}$ & $1455,2330,3650,4500$ & 1.33 & this work \\
\hline 4 & Chryse & $22^{\circ} \mathrm{N}, 46.5^{\circ} \mathrm{W}$ & $891,1534,2596,3600,4600$ & 1.06 & (3) \\
\hline 5 & Scopulus & $5^{\circ} \mathrm{N}, 278^{\circ} \mathrm{W}$ & 1900,2700 & 0.80 & this work \\
\hline 6 & Daedalia & $14.5^{\circ} \mathrm{S}, 127^{\circ} \mathrm{W}$ & $1475,2540,3960$ & 0.75 & this work \\
\hline 7 & Hellas & $43^{\circ} \mathrm{S}, 291^{\circ} \mathrm{W}$ & $1350 ?, 2295,4200$ & 0.68 & (4) \\
\hline 8 & Memnonia-A & $22^{\circ} \mathrm{S}, 165.5^{\circ} \mathrm{W}$ & 1593,2065 & 0.61 & this work \\
\hline 9 & Acidalia & $60^{\circ} \mathrm{N}, 30^{\circ} \mathrm{W}$ & $1000,1500,1950$ & 0.57 & this work \\
\hline 10 & near Arcadia & $31.7^{\circ} \mathrm{N}, 166.5^{\circ} \mathrm{W}$ & $880,1463,1925$ & 0.57 & (3) \\
\hline 11 & Isidis & $13^{\circ} \mathrm{N}, 272.5^{\circ} \mathrm{W}$ & 1100,1900 & 0.56 & (4) \\
\hline 12 & Angyre & $50^{\circ} \mathrm{S}, 42^{\circ} \mathrm{W}$ & $540,1140,1850$ & 0.55 & (4) \\
\hline 13 & Sirenum & $44^{\circ} \mathrm{S}, 166.5^{\circ} \mathrm{W}$ & $500,710,1000,1548$ & 0.46 & 5 \\
\hline 14 & South Hesperia & $32^{\circ} \mathrm{S}, 255^{\circ} \mathrm{W}$ & 900,1255 & 0.37 & this work \\
\hline 15 & Cassini-A & $13.7^{\circ} \mathrm{N}, 323.7^{\circ} \mathrm{W}$ & $354,653,928,1204$ & 0.35 & 5 \\
\hline 16 & Al Qahira & $20^{\circ} \mathrm{S}, 190^{\circ} \mathrm{W}$ & $141 ?, 353,715,1034$ & 0.30 & 6 \\
\hline 17 & South of Hephaestus & $10^{\circ} \mathrm{N}, 233^{\circ} \mathrm{W}$ & 500,1000 & 0.29 & 3 \\
\hline 18 & Mermnonia-B & $30^{\circ} \mathrm{S}, 180^{\circ} \mathrm{W}$ & $180,340,1000$ & 0.29 & 3 \\
\hline 19 & Al Qahira-A & $13.2^{\circ} \mathrm{S}, 183.5^{\circ} \mathrm{W}$ & $3357,530,731,994$ & 0.29 & 5 \\
\hline 20 & Ladon & $18^{\circ} \mathrm{S}, 29^{\circ} \mathrm{W}$ & $270,470,580,975,1300,1700$ & 0.29 & 3 \\
\hline 21 & South Polar & $83^{\circ} \mathrm{S}, 267^{\circ} \mathrm{W}$ & 850 & 0.25 & 7 \\
\hline 22 & West Tempe & $56^{\circ} \mathrm{N}, 78^{\circ} \mathrm{W}$ & $830 ?$ & 0.24 & this work \\
\hline 23 & overlapped by Newcomb & $22^{\circ} \mathrm{S}, 4^{\circ} \mathrm{W}$ & 380,800 & 0.24 & 3 \\
\hline 24 & Amazonis & $6^{\circ} \mathrm{N}, 168^{\circ} \mathrm{W}$ & 800 & 0.24 & this work \\
\hline 25 & South of Renaudot & $38^{\circ} \mathrm{N}, 297^{\circ} \mathrm{W}$ & 600 & 0.18 & 3 \\
\hline 26 & Holden & $25^{\circ} \mathrm{S}, 32^{\circ} \mathrm{W}$ & 260,580 & 0.17 & 3 \\
\hline 27 & Mangala & $0^{\circ} \mathrm{N}, 147^{\circ} \mathrm{W}$ & 300,570 & 0.17 & 3 \\
\hline 28 & overlapped by Schiaparelli & $5^{\circ} \mathrm{S}, 346.5^{\circ} \mathrm{W}$ & 140,560 & 0.17 & 3 \\
\hline 29 & Cassini & $24^{\circ} \mathrm{N}, 328^{\circ} \mathrm{W}$ & $321,547,930$ & 0.16 & 3 \\
\hline 30 & Southeast of Hellas & $58^{\circ} \mathrm{S}, 273^{\circ} \mathrm{W}$ & 225,500 & 0.15 & 3 \\
\hline
\end{tabular}

\footnotetext{
a Informal basin names reflect association with prominent fearures.

${ }^{b}$ Principal outer ring $D_{p}$ denoted by boldface.

${ }^{c}$ Quantity represents basin principal outer ring diameter normalized by planetary radius $(R=3393 \mathrm{~km})$.

${ }^{d}$ Parentheses indicate our reinterpretation of basin from original reference. (1) Schultz [1984], (2) McGill [1989]. (3) Schultz et al. [1982], (4) Wilhelms [1973], (5) Stam [1985], (6) Stam [1984], (7) Wood and Head [1976].
}

barrier to early Tharsis lavas [Scott and Tanaka, 1980] are fit by the inner ring of Daedalia basin shown in Plate $1 b$. The outer rings are attempts to fit Noachian materials to the south. However, the Noachian materials and channels are fit more consistently by Craddock et al.'s [1990] Daedalia basin, centered at $26^{\circ} \mathrm{S}, 125^{\circ} \mathrm{W}$. Large arcuate blocks of Noachian materials suggest to us a principal outer ring of $2200 \mathrm{~km}$ diameter and additional rings at 1100,1500 , and $3200 \mathrm{~km}$. The diameter chosen here for Craddock et al.'s [1990] Daedalia basin, $2200 \mathrm{~km}$, is comparable to that given in Table $1(2450 \mathrm{~km})$, so basin choice will not affect the statistics presented below. Interestingly, the scarps used by Craddock et al. [1990] to infer concentric basin ring structures face outward, or opposite to that found in smaller multiring basins such as Orientale. Scarp direction implies that faulting perhaps associated with formation of Daedalia's outer rings was directed away from the basin. Hence Daedalia concentric structure may have been influenced by relatively thin, weak lithosphere [cf. Melosh, 1982] and/or viscous relaxation of basin relief [cf. Thomas and Squyres, 1988].

Schultz and Glicken [1979] proposed that the arc defined by Noctis Labyrinthus and massifs in southem Tharsis were centered on a multiring basin. We find that the massifs and distribution of
Noachian materials can be fit better by a combination of North Tharsis (Table 1) and Daedalia [Craddock et al., 1990] basins. The structure of Noctis Labyrinthus [Tanaka and Davis, 1988] is consistent with that produced by localized doming and uplift [e.g., Suppe, 1985, pp. 242-246; Baer and Reches, 1989]. We have deleted the Tharsis basin [Schultz and Glicken, 1979] from our inventory and attribute the high elevation of Syria Planum and Noctis Labyrinthus to endogenic magmatic processes [e.g., Phillips et al., 1990]. Wrinkle ridges formerly associated with the Tharsis multiring basin [Schultz and Glicken, 1979] likely are related directly to endogenic activity in Tharsis [e.g., Banerdt et al., 1982; Watters and Maxwell, 1986]. Several major structures near Tharsis are difficult to explain by using a multiring basin paradigm. The V-shaped, concave north boundary between high standing Noachian terra (units Npld, Nf, Nb; brown in Plate 1) and younger plains units to the south (units $\mathrm{Hpl}_{3}, \mathrm{Hr}$; violet in Plate 1) in Thaumasia is structural, perhaps resulting from normal or reverse faulting. This prominent regional boundary is not fit well by any single circular arc, nor can it be attributed easily to known or postulated impact basins in western Mars (see Plate 1b). Similarly, the north-south trending Coprates Rise of probable Noachian age [Roth et al., 1980] is not concentric to Tharsis area basins. The 


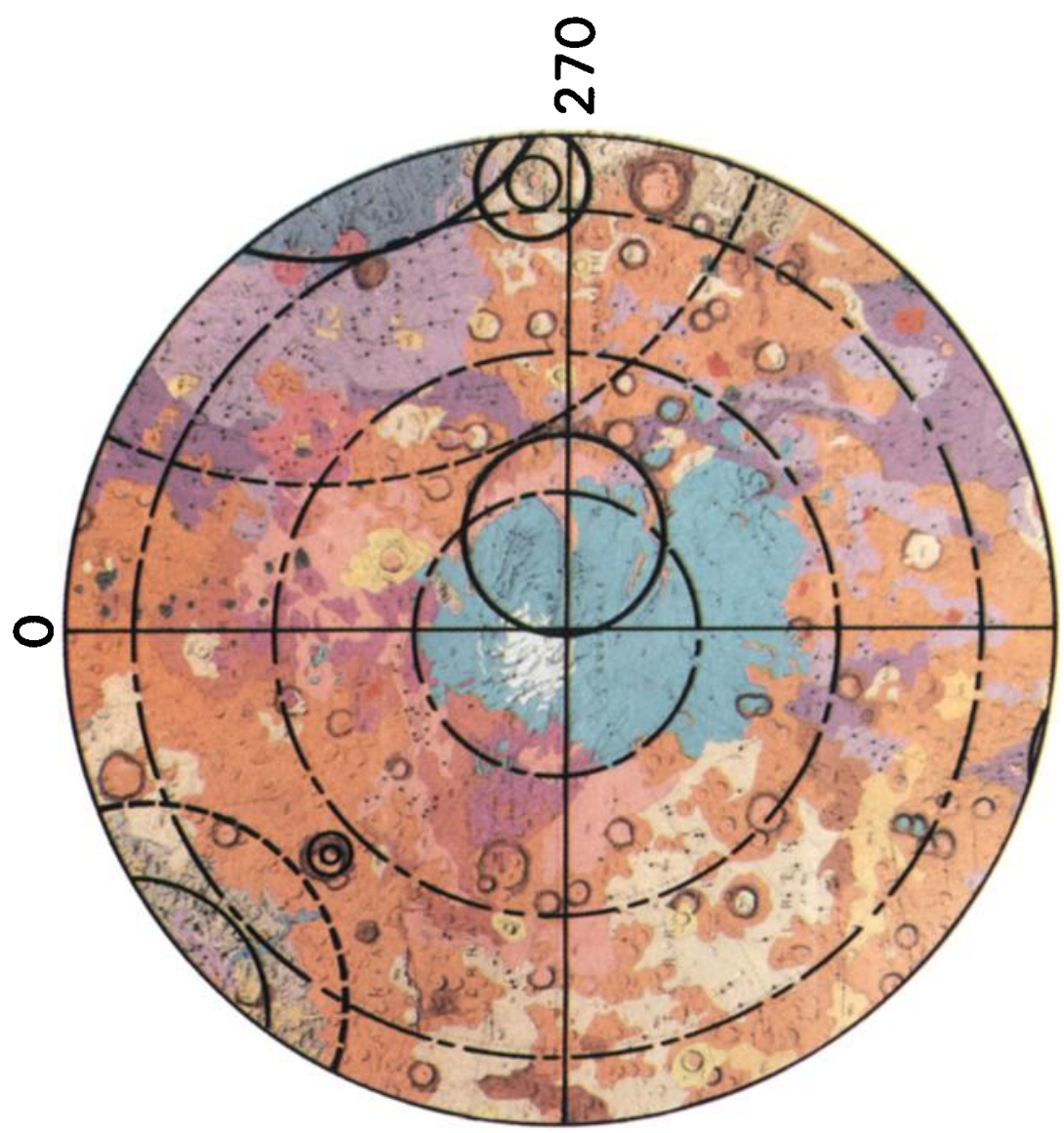

क 5

ํํํ

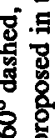

尊

के

趋

离

容

送

害。

究

응

品

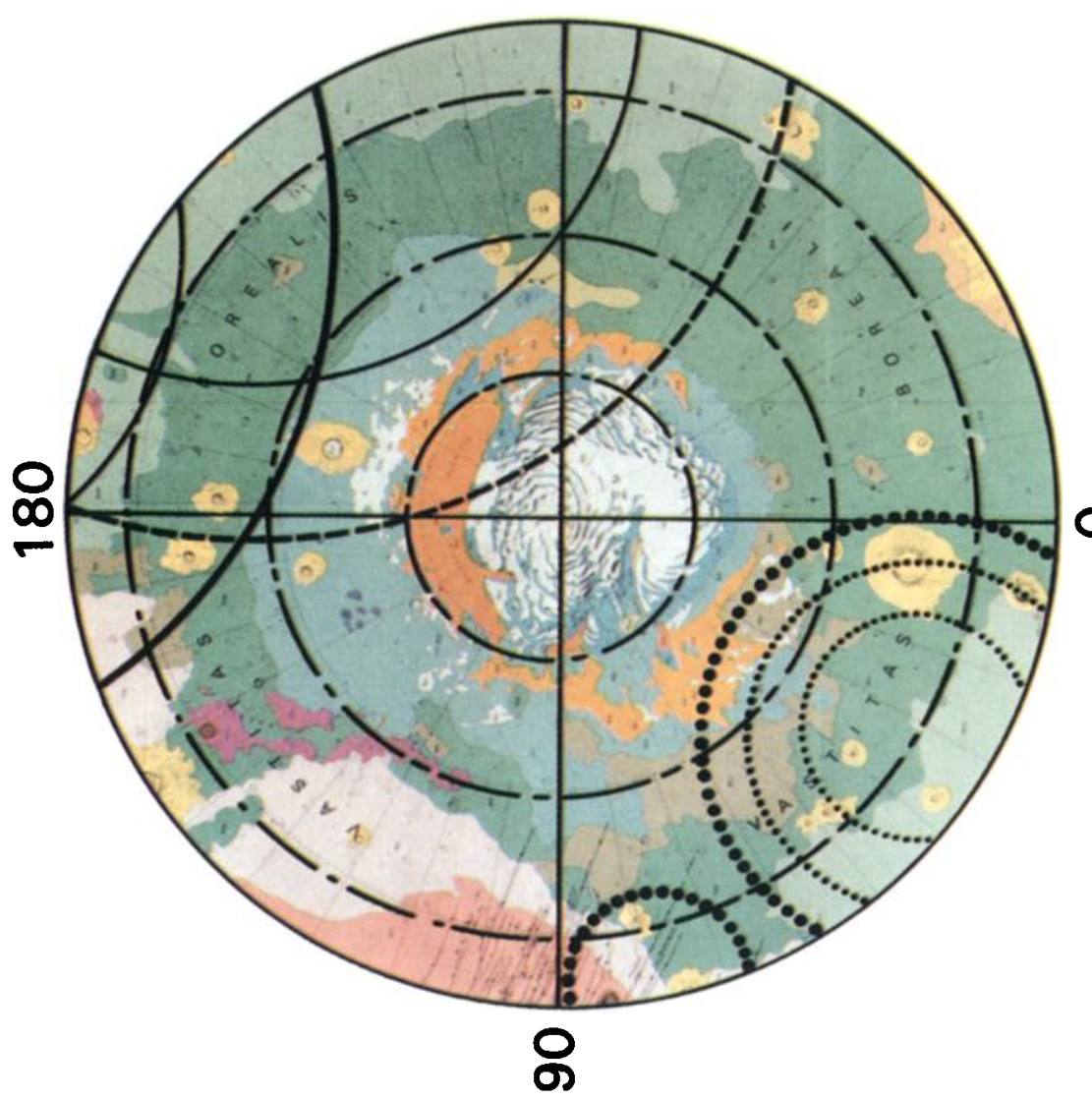

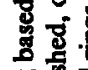

of

5

형

实

要

글

㿣

용

을

E 8

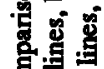

客

280 응

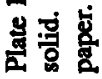




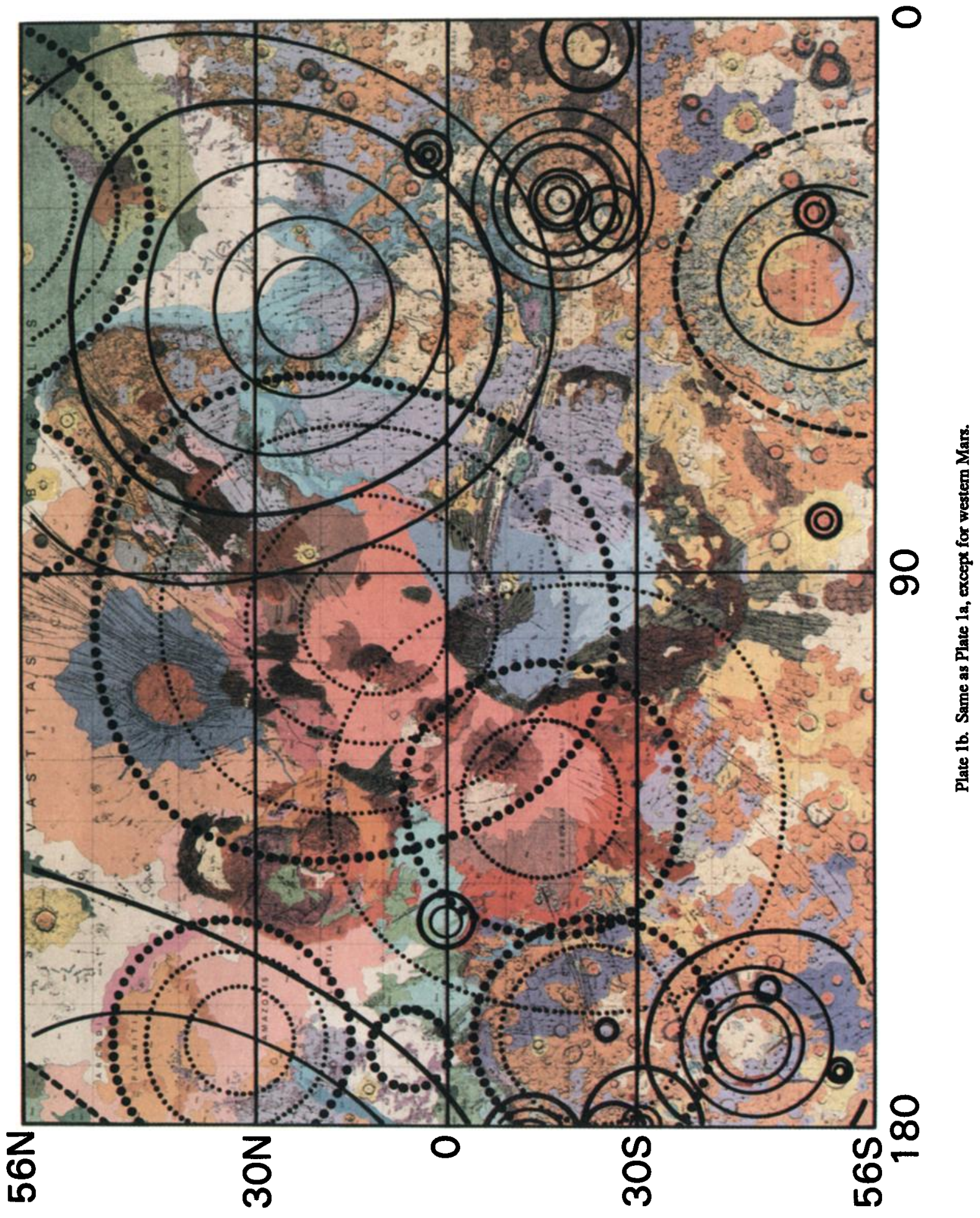




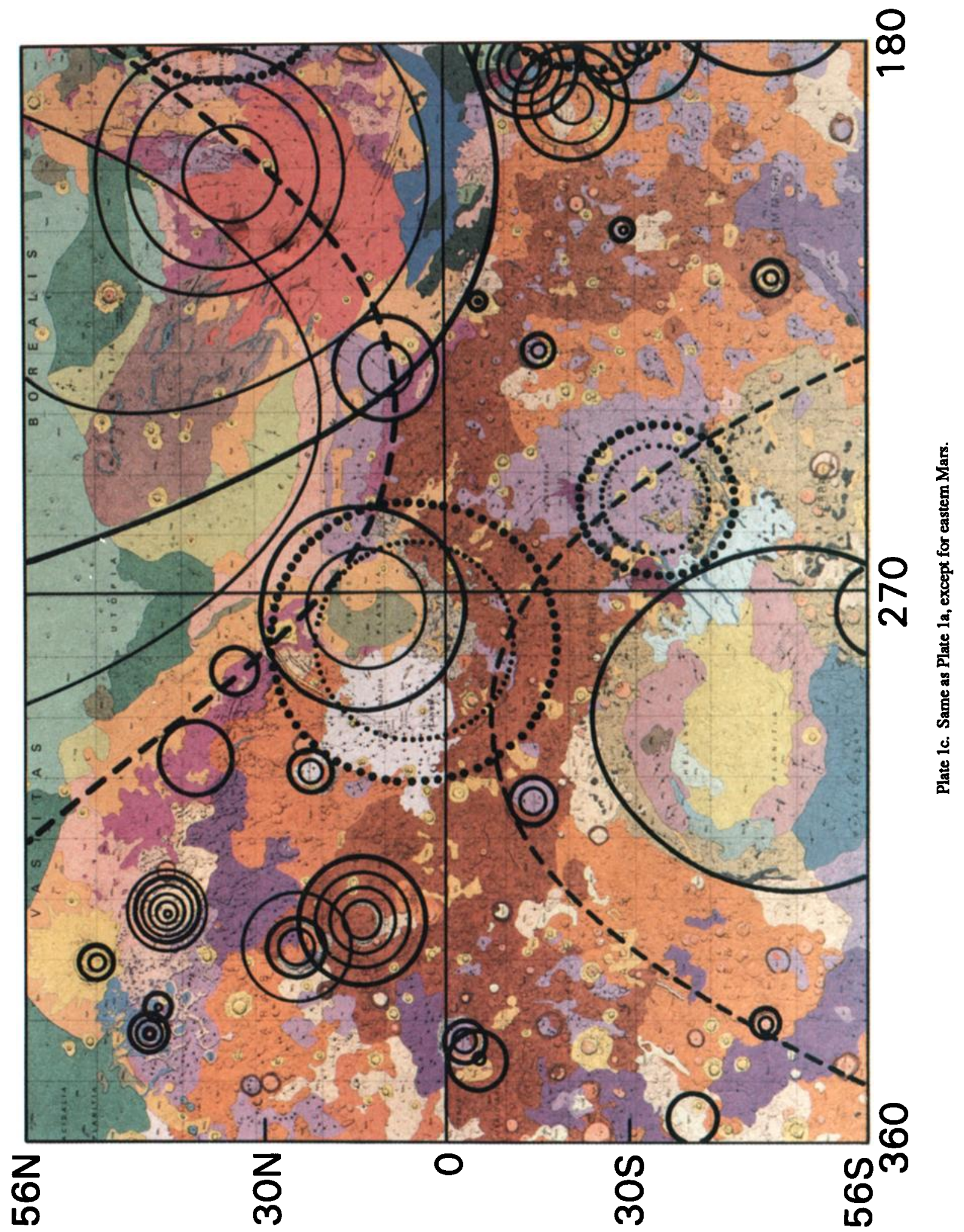



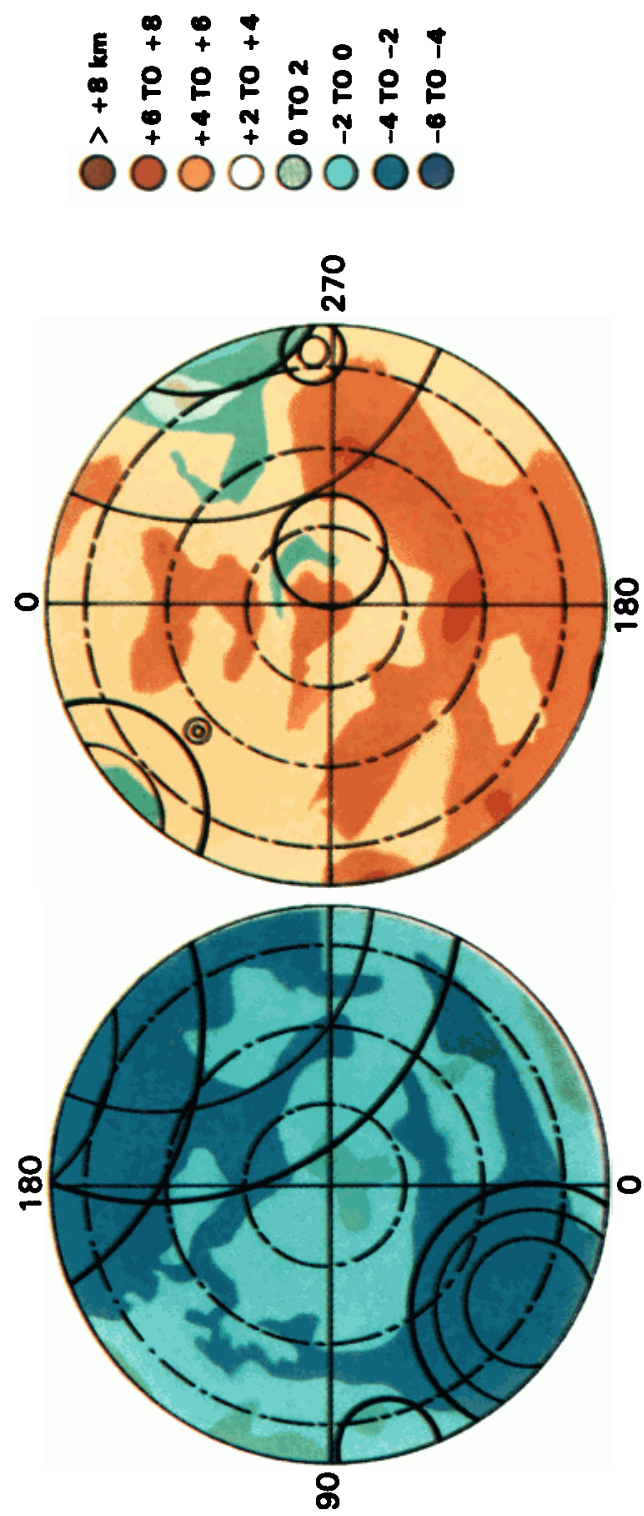

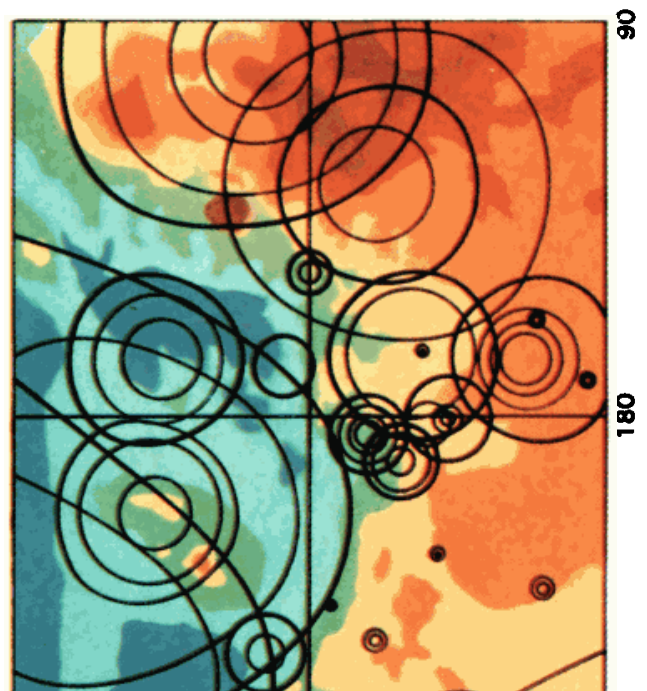

옹

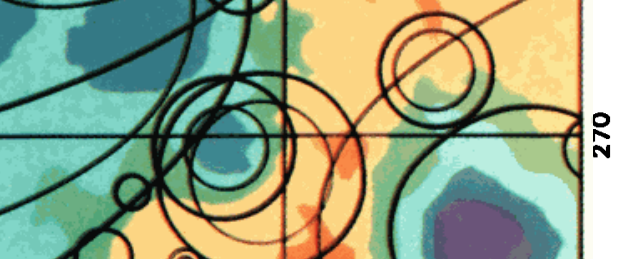

퐁
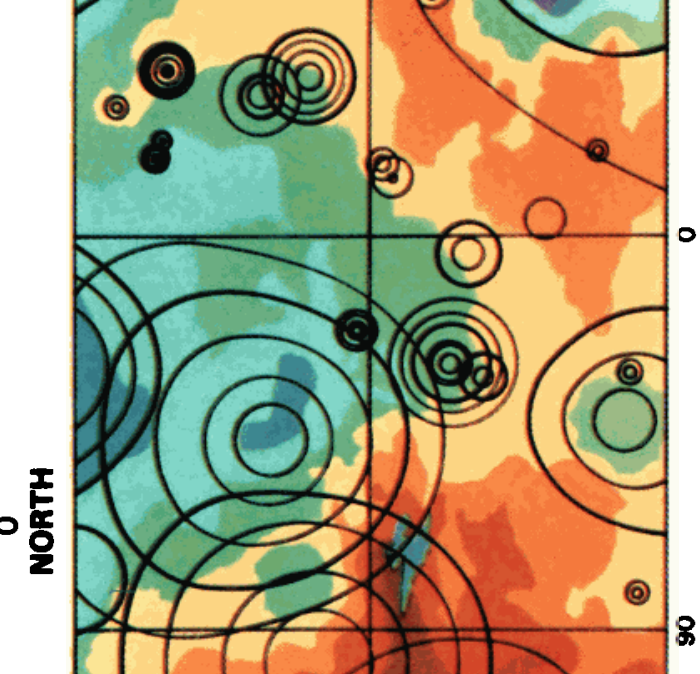

8

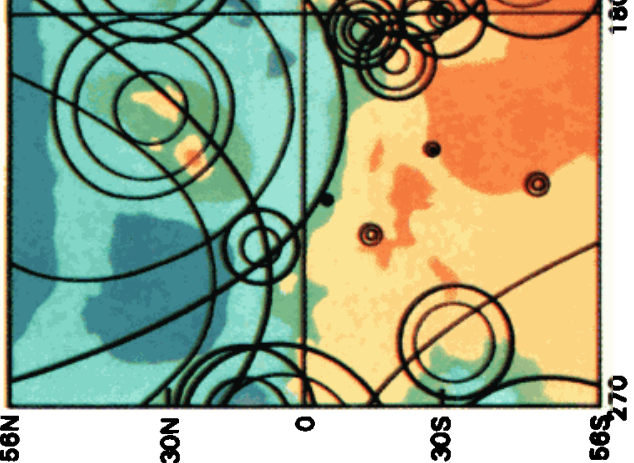



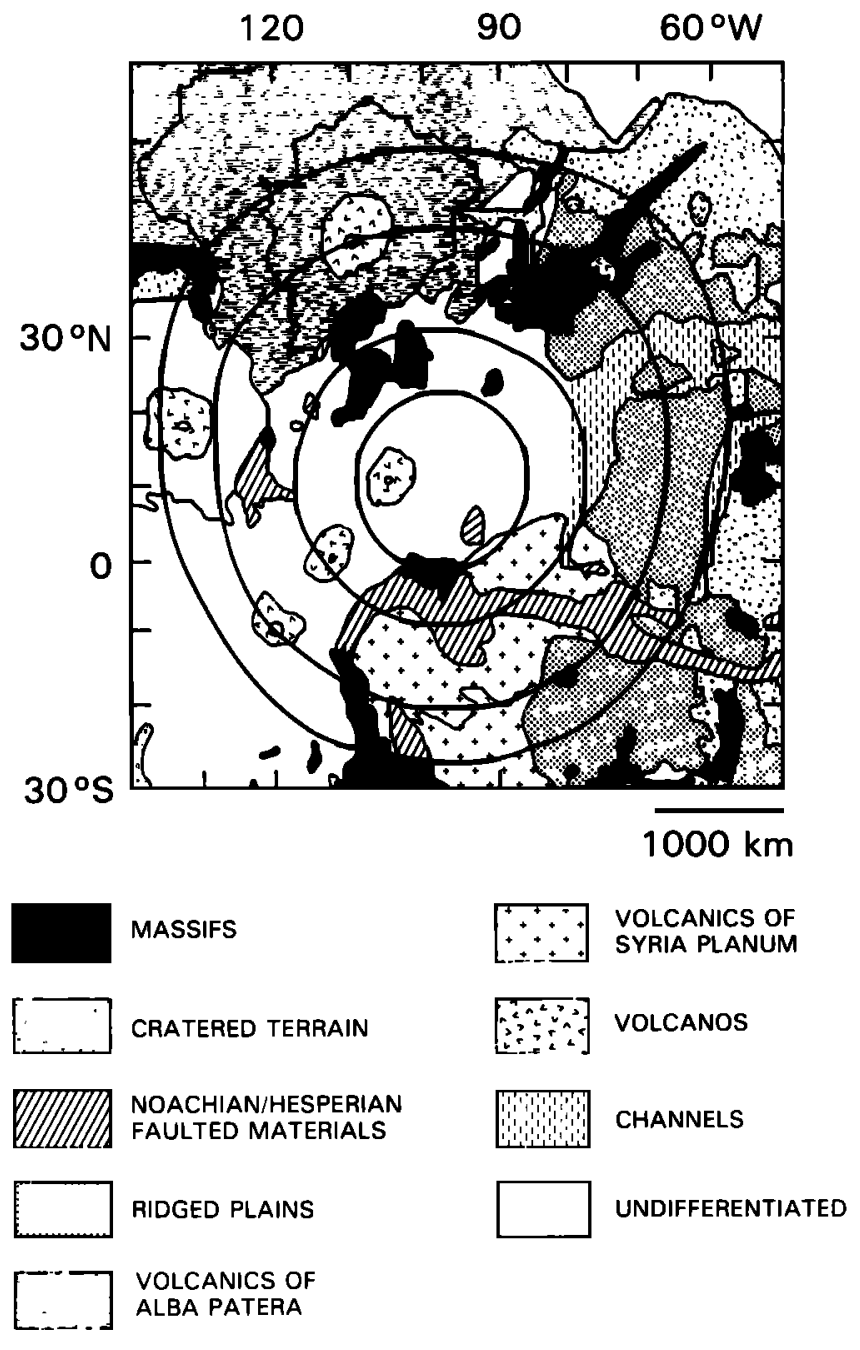

Fig. 2. Geologic sketch map of the North Tharsis basin.

large scale deformation represented by these early structures in Thaumasia and Coprates remains difficult to explain by either internal processes or large impacts.

A large basin in Memnonia is inferred from the distribution of Noachian and Hesperian ridged plains units, the westward change in trend of Mangala Valles, and topography (Figure 3; basin 8 in Table 1). The inner ring of Memnonia-A basin is defined by the outer arcuate contact between Noachian and Hesperian age ridged plains materials (units $\mathrm{Npl}, \mathrm{Hpr}$ ) and surrounding $\mathrm{Npl}_{1}$ units. The westem extent of Nplr ridged plains units and the associated Memnonia Fossae graben sets are controlled apparently by a local topographic increase within the basin (see Plate 2 [Roth et al., 1989]). Possible massif remnants occur in the northwest sector as an arc of Noachian basement (unit Nplh; brown in Plate 1) material. The outer, principal ring is defined by curving reaches of Mangala Valles in the northeast as well as scattered massifs and rare volcanos. This ring corresponds also to the boundary of the topographic basin to the southeast (Plate 2). The interring region contains massifs, ridged plains units, and chaotic terrain. However, concentric structure closer to basin center is difficult to recognize on the Scott and Tanaka [1986] map, and more detailed mapping is necessary to resolve these structures.

The distribution of knobby terrain in Arcadia is consistent with the occurrence of an underlying multiring basin (Figure 4; basin 10

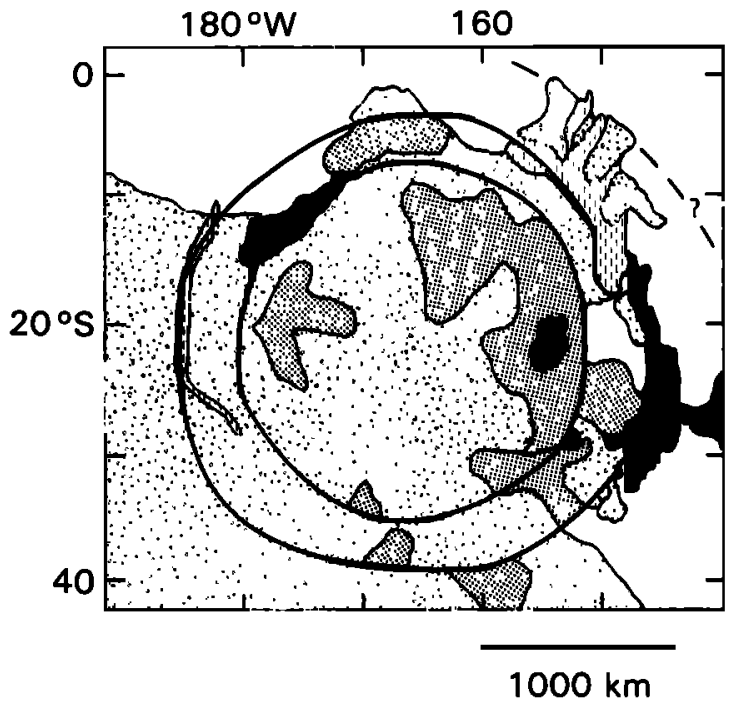

MASSIFS

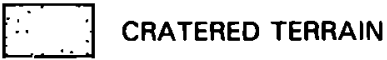

RIDGED PLAINS

CHANNELS

UNDIFFERENTIATED

Fig. 3. Geologic sketch map of the Memnonia-A basin.

in Table 1). An inner ring is defined by the arcuate contact between interior plains units (units Aa3, Aa4) and knobby terrain (unit HNu). An outer ring is inferred from the boundary between this irregular annulus of knobby terrain and the surrounding plains units.

The northwestern and northeastern margins of Tempe Terra may be controlled by impact basins. The West Tempe basin (basin 22 in Table 1) is inferred by the arcuate north facing escarpment in Tempe Terra (Plate 1b). A large subcircular topographic basin in Acidalia Planitia (Plates $1 a$ and $1 b$; basin 9 in Table 1) may form the northeast margin of Tempe Terra and control the distribution of knobby terrain in the region (Plate $1 b$ ). Radial topographic gradients (Plate 2) and the distribution of Noachian terra and knobby materials may support an interpretation of three basin rings.

The Isidis, Argyre, and Hellas basins lack clear equivalents of Orientale type multiring structure [Wilhelms, 1973]. Discontinuous inward facing scarps partly bound the rugged annuli of both the older Hellas and relatively young Argyre basins. The annuli are cut by concentric grabens and normal faults. Numerous arcuate, discontinuous canyons that occur at least $2100 \mathrm{~km}$ from Hellas' center may have formed in response to the impact [Wichman and Schultz, 1989]. The location of an inner ring for Hellas remains elusive. Massifs and source areas of radial channels found in northeast Hellas $400-500 \mathrm{~km}$ inside the principal ring may indicate an interior ring of $1350 \mathrm{~km}$ diameter. Structures inside Hellas' principal ring may be obscured by a possible superimposed basin as suggested by an offset topographic minimum (Plate 2) and quasi-circular distribution of $\mathrm{Hh}_{2}$ materials (Plate 1c). This speculative younger basin has center $44^{\circ} \mathrm{S}, 295^{\circ}$ 


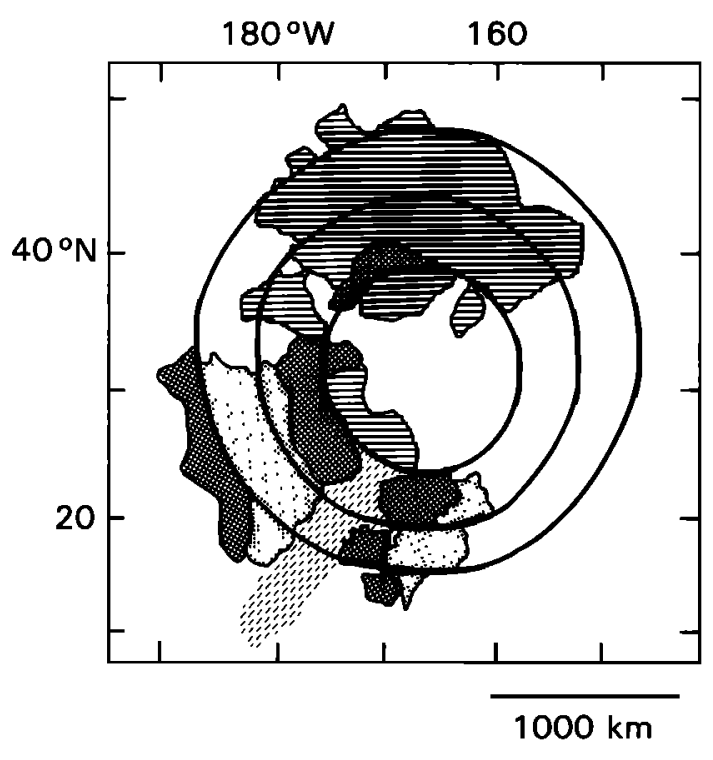

SMOOTH PLAINS

KNOBBY TERRAIN

RIDGED PLAINS

CHANNELS

UNDIFFERENTIATED

Fig. 4. Geologic sketch map of the Amazonis basin.

$W$ and approximate diameter of $1500 \mathrm{~km}$. Significant relief of $>3$ $\mathrm{km}$ and $>6 \mathrm{~km}$ is supported by Argyre and Hellas, respectively [Wu et al., 1986; U.S. Geological Survey, 1989]. Isidis can be traced across the planetary dichotomy boundary, although its morphology differs on either side [Grizzaffi and Schultz, 1989]. A radial trough parallel to Amenthes Rupes that extends from the Isidis inner ring southeastward beyond its annulus (Plate 1c) may be basin related [Wichman and Schultz, 1989]. Isidis grabens and massifs appear to overprint the Scopulus basin (Plate 1c; basin 5 in Table 1). The Scopulus inner ring is defined by the prominent inward facing arcuate scarp (Scopulus-Oenotria) south of Syrtis Major Planum that is not concentric to Isidis. A more subtle outer ring is inferred from concentric inward facing scarps to the south and patches of Hesperian plains units.

Chryse basin structure [Schultz et al., 1982] is characterized by a central depression partly encircled by massifs and surrounded by a very wide annulus broken by radial and concentric structures (Plate 1b). Most wrinkle ridges concentric to Chryse [Chicarro et al., 1985] and radial channel wall scarps [Schultz, 1985] occur between the second and third rings ( $1500-2600 \mathrm{~km}$ diameter). Relief across the basin structure is small, and no inward facing outer scarp or uplifted Cordillera-type rim is apparent. Instead, its outer boundary $(D=3600 \mathrm{~km})$ is inferred by the locations of concentric outflow channels, floor-fractured craters, and chaotic terrain in Margaritifer Sinus. The Chryse central depression is quite small relative to the structure's total radius, implying that strain associated with the impact was distributed over a very large area.
Two of the largest basins suggested for Mars, Elysium [Schultz, 1984] and Utopia [McGill, 1989], share common attributes including poorly defined concentric structure, shallow topographic profiles, and associated volcanism (Plates $1 a$ and $1 c$ ). Viking orbiter gravity data [Sjogren, 1979] suggest the presence of a mascon below Utopia [MCGill, 1989]. Inward facing Cordillera type outer rings cannot be identified for either basin, making unambiguous determination of basin diameter difficult. However, the location of the planetary dichotomy boundary in eastern Mars defines segments of small circles concentric to the suggested centers of these speculative impact structures [Frey and Schultz, 1989, This issue]. It is possible that the geometry of the planetary dichotomy boundary in eastern Mars was influenced by concentric structures associated with the suggested Elysium and Utopia basins. We choose basin diameters to coincide with the concentric arcs of highland units along the boundary because these arcs define the topographic Elysium and Utopia basins proper.

The eastern and southem hemispheres of Mars are curiously underpopulated by multiring basins. For example, the region south of the equator between $180^{\circ}$ and $270^{\circ} \mathrm{W}$ contains extensive exposures of Noachian materials and Noachian-Hesperian ridged plains [Tanaka et al., 1988] and unmapped impact basins of Noachian age may occur in this area. The occurrence of massif knobs, fretted terrain, and channels east of Hellas [Squyres, 1979] may be influenced by possible basins such as South Hesperia (Plate 1c; basin 14 in Table 1). Similarly, the south polar region presently shows few basins (Figure 1 and Plates $1 a$ and 2). The South Polar basin [Wood and Head, 1976] is not well mapped and is represented only by a single incomplete Cordillera type scarp. Further detailed mapping of these regions is needed to clarify the number and distribution of impact basins in these older units.

Wilhelms and Squyres [1984] proposed that the northern plains are underlain by a $7700-\mathrm{km}$-diameter Borealis impact basin. Although little direct evidence of a Borealis basin can be found [Frey et al., 1986; Frey and Schultz, 1988] and other large basins apparently control much of the regional geology [Schultz, 1984; McGill, 1989; Frey and Schultz, 1989], Wilhelms and Squyres' [1984] hypothesis remains a possible mechanism for producing the northern lowlands. The apparent paucity of evidence for Borealis precludes its inclusion in our basin inventory, but for completeness its potential contribution to basin statistics is evaluated below (see Table 2 and Figure 5). However, if Borealis did form it occurred very early, before the basins shown in Figure 1. The morphology of large Martian basins discussed below suggests that an early Borealis basin probably would not resemble Orientale in ring structure or morphology and would be very shallow, with little positive relief.

\section{DISCUSSION}

The record of multiring impact basins represents a window into the structure of early Mars, and study of these basins can clarify a number of important problems. In particular, we discuss revised basin statistics and the possible influence of planetary curvature and lithospheric thickness on the morphology of Martian basins. The large number of basins shown in Plate 1 implies that substantial thicknesses of volcanic material and ejecta should occur in Hesperian and Noachian units, yet geologic mapping has been unable to identify these deposits. Last, the spatial association of multiring basins and the planetary terrain dichotomy, Elysium, and Tharsis suggests that basin-forming impacts may have interacted with mantle processes to help localize these important volcanic regions. 


\section{Multiring Basin Morphology and Basin Size}

The choice of ring diameter for use in statistical and morphologic studies is more difficult to determine for multiring basins than for smaller craters or basins. We suggest that the morphologic variations of Martian basins motivate a refinement of the "multiring basin" class of structures into three subclasses. Smaller multiring basins on Mars are comparable dimensionally, morphologically, and structurally to Orientale, so assignment of basin diameters for these structures is straightforward. Orientale type multiring structure can be recognized for Martian basins larger than about $300 \mathrm{~km}$ in diameter [Strom et al., 1990] but smaller than Argyre $(D=1850 \mathrm{~km})$. For example, Ladon [Schultz et al., 1982] $(D=975 \mathrm{~km})$ shows structures equivalent to the Inner and Outer Rook rings and Cordillera outer scarp of Orientale $(D=930 \mathrm{~km})$ [Head, 1974]. We choose the Cordillera scarp equivalent to define these basin diameters.

Basins of Argyre size or larger but smaller than Chryse ( $D=$ $3600 \mathrm{~km}$ ) are characterized by a rugged faulted annulus, central depression, and shallower topography relative to the basin diameter. These basins (e.g., Isidis, Hellas) do not show clear analogs or identifiable remnants of Orientale type structure [Wilhelms, 1973]. Basins as large as Chryse or larger (e.g., Elysium, Utopia, Borealis?) display vague concentric structure or multiple rings reminiscent of Valhalla on Callisto [Smith et al., 1979] and exceedingly shallow relative relief. The current heights of rim massifs and scarps of basins such as Ladon $(D=975 \mathrm{~km})$ and Hellas $(D \sim 2300 \mathrm{~km})$ rarely exceed $2-3 \mathrm{~km}$. Relief along rings inferred for the Chryse basin may decrease outward from the 1-2 $\mathrm{km}$ high massif ring that bounds the central depression. Although basin ring relief probably depends on how and when the rings were formed, the maximum relief of concentric massifs and scarps surrounding Martian basins appears to be relatively constant, regardless of basin diameter. The progressive shallowing of basin profiles with increasing diameter is consistent with similar relationships noted for much smaller craters and basins [e.g., Howard, 1974; Wood and Head, 1976; Wood, 1980; Croft, 1981]. Diameters of Martian basins larger than Argyre are taken to be the maximum extent of either Argyre type rugged annuli or prominent concentric topography and structure. Onset diameters for these basin subclasses are only approximate because of the relatively small number of basins and because lithospheric thickness and planetary curvature may contribute to large basin morphology.

\section{Basin Statistics and the Impactor Population}

Cumulative frequency distributions of Martian multiring basins are shown in Figure 5. Best fit lines to the data were obtained by using the least squares method with $\sqrt{ } N$ weighting [Bevington, 1969] (Table 2). We find that Martian basins $>500 \mathrm{~km}$ in diameter can be fit quite well by a shallow power law distribution with a slope of $-0.93 \pm 0.1$ (see case A, Table 2). The data also can be fit at least as well by two lines defined by the size frequency distribution of basins $<1800 \mathrm{~km}$ and $>1800 \mathrm{~km}$, respectively (cases $\mathrm{E}$ and $\mathrm{F}$, Table 2). Basins of Argyre size and larger $(D=1850 \mathrm{~km})$ follow a power law distribution with slope of $-1.7 \pm 0.45$, whereas the smaller basins define a slope of $-0.75 \pm 0.16$ (Figure $5 a$ ). Slopes of about -2 have been inferred for populations of multiring basins on Mercury and the Moon [see Woronow, 1977, 1978], although slopes can change significantly for smaller craters and basins [e.g., Chapman and McKinnon, 1986; Strom, 1987]. Note
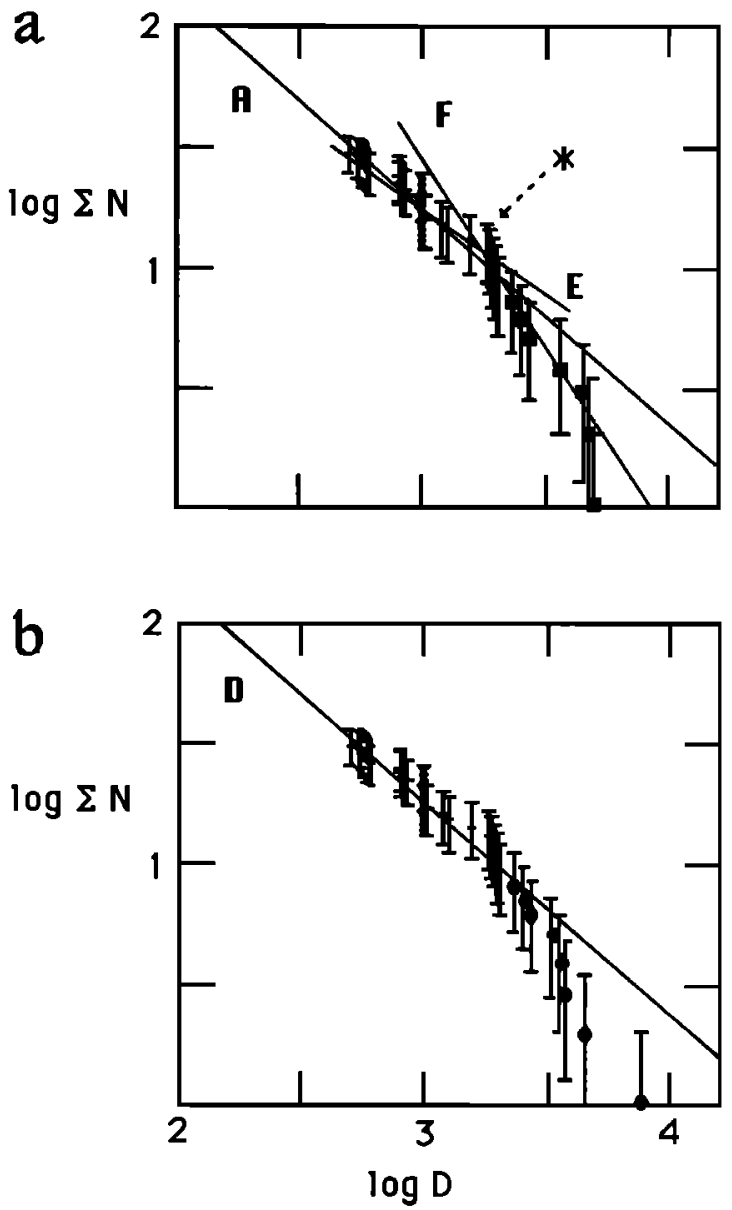

Fig. 5. Cumulative frequency distribution of Martian multiring basins $>500$ $\mathrm{km}$ in diameter (unbinned data). Cumulative number normalized to surface area of Mars. Basins $>2300 \mathrm{~km}$ diameter shown by dots; letters correspond to $\mathfrak{V}$ weighted least squares fits from Table 2. (a) Data from Table 1 (case A). Argyre basin denoted by asterisk. (b) Basin data modified by using smaller diameters for Elysium and Utopia and including Borealis (case D).

that this change in slope occurs in the same diameter interval as the significant change in basin morphology previously described. The change in slope of the curnulative frequency curve near the diameter of Argyre could reflect a change in impactor velocity [Schultz, 1988] or size-frequency distribution, depopulation of basins smaller than Argyre by resurfacing, or interaction between lithospheric thermomechanical structure and basin diameter.

Plots of relative crater frequency ( $R$ plots [Crater Analysis Techniques Working Group, 1979]) show directly how the population of multiring basins relates to that defined by smaller craters. Addition of data within diameter bins on an $R$ plot does not change points elsewhere on the diagram. Data in Figure 6 are normalized to a differential slope of -3 ( -2 cumulative slope: see Gurnis [1981]) [Strom, 1977]. Comparison of our data with those of Barlow [1988] indicates reasonable agreement on relative abundance of basins with diameters between 500 and $1000 \mathrm{~km}$. However, calculation of standard $1 \sigma$ uncertainties from both data sets indicates that ours is more complete for basins $>500 \mathrm{~km}$ in diameter. Figure $6 b$ shows the relative frequency distribution of lunar craters [Strom, 1977] and basins [Wilhelms, 1987]. The combined Martian cratering record (Figure 6a) is similar to that of the Moon (Figure 6b) and Mercury [Strom and Neukum, 1988], except for craters $\sim 100-800 \mathrm{~km}$ in diameter. Formal $1 \sigma$ uncertainties in crater abundance at these larger diameters are small 
TABLE 2. Least Squares Fit to Unbinned Cumulative Frequency Data From Martian Basins

\begin{tabular}{cccc}
\hline Case & Slope & Intercept & $R^{*}$ \\
\hline & & & \\
A & $-0.932 \pm 0.093$ & $4.031 \pm 0.275$ & 0.970 \\
B & $-0.892 \pm 0.086$ & $3.935 \pm 0.255$ & 0.973 \\
C & $-0.944 \pm 0.095$ & $4.064 \pm 0.281$ & 0.963 \\
D & $-0.908 \pm 0.088$ & $3.981 \pm 0.261$ & 0.966 \\
E & $-0.747 \pm 0.164$ & $3.499 \pm 0.474$ & 0.971 \\
F & $-1.666 \pm 0.445$ & $6.471 \pm 1.491$ & 0.972 \\
\hline
\end{tabular}

Case A, data from Table 1. Case B, case A including Borealis $(D=$ $7700 \mathrm{~km})$. Case C, next smaller ring used as diameter for Elysium $(3600$ $\mathrm{km})$, Utopia $(3300 \mathrm{~km})$. Case D, case C including Borealis. Case E, basins from Table 1 with diameters < Argyre $(D=1850 \mathrm{~km})$. Case $F$, basins from Table 1 with diameters 2 Argyre.

W $R$ is correlation coefficient. Basin data were analyzed in $\log -\log$ form by using least squares fitting with $\mathrm{V} N$ weighting.

for both Mars and the Moon. This apparent deficiency of large Martian craters relative to the Moon is eliminated for craters $<300$ $\mathbf{k m}$ in diameter when lunar and Martian orbital velocities are taken into account [Schultz, 1990]. Nevertheless, fewer basins less than
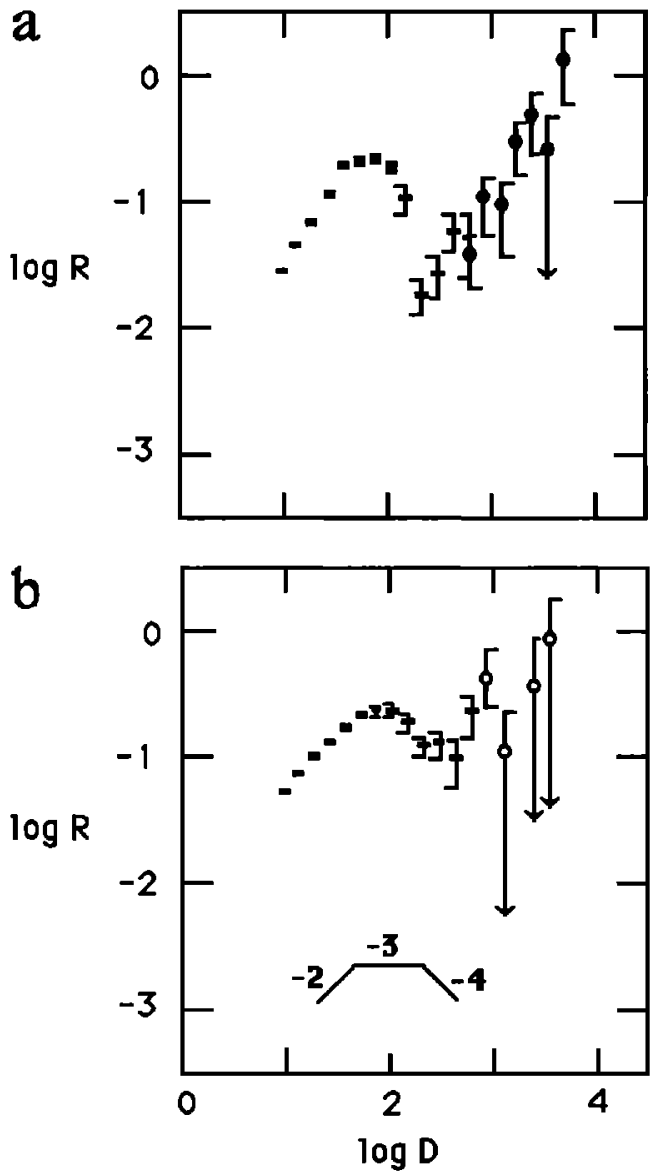

Fig. 6. Relative frequency ( $R$ plot) diagrams of Martian craters and basins. Data normalized by size frequency distribution with differential slope of -3 ( -2 cumulative) and binned by using the standard $D \sqrt{2}$ intervals. Inset in Figure $6 \mathrm{~b}$ shows orientations of crater populations having given differential slopes. (a) Craters and basins on Mars; data from Table 1 (dots) and Barlow [1988]. (b) Craters and basins on the Moon; data from Strom [1977] (craters) and Wilhelms [1987] (basins, open circles).
$-1000 \mathrm{~km}$ in diameter are currently tabulated on Mars relative to the Moon, given the considerable uncertainties in the lunar basin data (see Figure $6 b$ ). Large partly buried craters are common on Mars but were not included in Barlow's [1988] data set. The apparent deficiency of large Martian craters probably at least partly reflects resurfacing processes and counting techniques rather than fundamental differences in impactor populations [cf. Barlow, 1990]. Thus, given current crater counts and this interpretation (but see Ryder [1990]), the relative abundances of craters and basins on the terrestrial planets appear to be comparable.

Figures 5 and 6 are composites because they are derived from a variety of surfaces of differing age and do not represent a single counting surface (W.B. McKinnon, personal communication, 1989). In contrast, if the counting surface were everywhere the same age it might be difficult to find all of the smaller basins having comparable degradation state (age) as the largest basins. These uncertainties highlight the need to count degraded or partly buried structures in addition to the clearly superposed craters and basins.

We examined four cases to test the effect of basin diameter selection on the size frequency statistics (Table 2). Results from two of these cases are shown in Figure 5. Selection of much smaller diameters for the Elysium and Utopia basins (case D, Table 2) and inclusion of the postulated Borealis basin (Figure 5b: our "worst-case" scenario) result in a size frequency distribution indistinguishable statistically from that obtained by using the diameters given in Table 1 (Figure 5a). Comparable results were obtained by using binned data and $R$ plots. Thus basin size frequency statistics are insensitive to even large errors in determination of basin ring diameters. This finding suggests that Figures $5 a$ and $6 a$ are adequate approximations to the Martian crater and basin record even allowing for errors in determination of basin ring diameters and inclusion of speculative basins.

Inversion of the record of multiring basins on Mars for the parent impactor population is a difficult problem. Three items need to be addressed before a rigorous inversion is possible: (1) an accurate inventory of impact basins, (2) removal of the effects of resurfacing or equilibrium/saturation [Chapman and McKinnon, 1986] on basin size frequency statistics, and (3) realistic physical scaling relations between multiring basins and the impacting objects. This paper represents an attempt to document the inventory of Martian impact basins to large diameters. The apparent difficulty in recognizing large and relatively old basins such as Hellas, Chryse, and Utopia suggests that the effects of resurfacing on basin statistics can be quite significant. Until scaling laws relating impactor dynamics to multiring basin formation become available, the basin record on Mars could probably be used as a rough, first-order approximation to its parent impactor population. Scaling relationships for large multiring basins must consider energetic impacts into rheologically layered spherical targets and explicitly include formation of the assemblage of structures associated with these impact basins (e.g., rugged annuli). Results of these calculations will be important for quantitatively linking Mars' basin record to lithospheric structure and impactor dynamics [e.g., Hartmann and Vail, 1986; Benz et al., 1989].

\section{Basin Ring Expression and Spacing}

Ratios of the diameters of adjacent rings range from 1.3 to 2.2 and are independent of basin size. Curiously, ring spacing in several basins including Chryse, North Tharsis, and Argyre actually decreases outward. Ring spacing should increase outward 
from basin center if the source of ring forming stress decreased in magnitude outward and lithospheric thickness and strength remained constant. In this case, the lithosphere would be thick or strong enough for the cannonical $\sqrt{ } 2$ ratio of adjacent rings expressed most strongly on the Moon [Pike and Spudis, 1987] to have dominated. Ring spacing would presumably scale with transient cavity diameter [Melosh, 1989, p. 179]. However, plots of annulus width versus inner or outer ring radii show large scatter, suggesting that annulus width may not simply be a function of transient cavity or final basin diameter. Indeed, the distance between adjacent rings has been used as an estimate of lithospheric thickness at the time of ring formation for very thin lithospheres (see McKinnon [1981], Pike and Spudis [1987], and Melosh [1989] for discussion). However, ring spacings of Martian basins larger than Argyre (e.g., Chryse, Table 1) exceed $600-1000 \mathrm{~km}$. These large spacings would imply either extraordinarily thick lithosphere or a number of undetected rings.

Pike and Spudis [1987] and Wichman and Schultz [1989] recently proposed basin rings for Argyre, Isidis, and Hellas that differ from those listed in Table 1. We infer ring diameters for Argyre of 540, 1140, and $1850 \mathrm{~km}$ (boldface indicates principal ring), whereas Pike and Spudis [1987] note rings at 410?, 630, 800,1100 ?, 1360 ?, and 1900 ? $\mathrm{km}$. Both sets of ring diameters contain a value of $1850-1900 \mathrm{~km}$, for example, but we differ from Pike and Spudis in its interpretation. The ring diameters for Isidis are $1100,1900 \mathrm{~km}$ (this work); $700,1500,3000,3800 ? \mathrm{~km}$ [Pike and Spudis, 1987]; and 1480, 1700,3200 km (averages of values from Wichman and Schultz [1989]). Our value for the principal ring, based on a best fit to the outer limit of the Isidis annulus, $1900 \mathrm{~km}$, exceeds the Pike and Spudis estimate by $27 \%$. Wichman and Schultz apparently chose the Scopulus-Oenotria scarp as the Isidis principal ring. The diameters for Hellas are 1350 ?, 2295, $4200 \mathrm{~km}$ (this work); 840?, 1200?, 1700?, 2200, $3100,4400,5500$ ? km [Pike and Spudis, 1987]; and 2050, 3200, $3580,4300 \mathrm{~km}$ [Wichman and Schultz, 1989]. In this case, our value for the principal ring is comparable (4\% larger) to that of Pike and Spudis, but Wichman and Schultz list a somewhat larger diameter. By comparison, Barlow [1988, 1990] uses the diameter of the central depression for large structures such as Hellas $(N$. Barlow, personal communication, 1989). In general, we tend to list fewer rings than other workers but there appears to be no consensus on the definition or interpretation of Martian basin rings.

\section{Multiring Basins and Target Properties}

Lithospheric thickness appears to be an important factor in the overall development of concentric basin structure [Melosh and McKinnom, 1978] although it may not be the dominant influence on ring spacing [Melosh, 1989]. Formation of Orientale type basins is favored by relatively thick or strong lithosphere and a transient cavity depth less than or not greatly in excess of the lithospheric thickness. These conditions would probably occur later in Martian history once the lithosphere had cooled and thickened sufficiently. For example, inversion of Viking orbiter gravity data shows that Isidis is largely uncompensated [Solomon et al., 1983]. Subsequent basin fill by high density materials produced its mascon [Sjogren, 1979] and concentric grabens within the Isidis annulus imply an effective elastic lithosphere $>120 \mathrm{~km}$ thick [Comer et al., 1985]. Hellas topography may be fully compensated, assuming elastic lithosphere $130 \mathrm{~km}$ thick [Sjogren and Wimberley, 1981]. In contrast, basin-forming impacts that occurred earlier in Martian history could have penetrated a thinner, hotter, weaker lithosphere, and impact basin morphologies may have been characterized by shallow topographic profiles and multiple rings. The relief of such early impact basins may have been reduced over longer time scales by viscous relaxation of topography [cf. Melosh, 1982]. On the basis of apparent superposition and topography, Elysium, Utopia, Chryse, North Tharsis, and Daedalia [Craddock et al., 1990] appear to be some of the oldest impact basins on Mars and they potentially formed in relatively thin, weak lithosphere. The morphology and present day topography of the largest Martian basins suggest that impact into the Martian lithosphere during Late Heavy Bombardment may have been analogous to impact into icy satellite lithospheres during their heavy bombardment.

Diameters of large Martian basins such as Chryse can be significant fractions of the radius of Mars (see Table 1). The equivalent value for Orientale basin diameter normalized by lunar radius, 0.53, is comparable to that of Argyre, 0.55 (Table 1) or Caloris on Mercury, 0.53. Because Orientale, Argyre, and Caloris have similar normalized diameters but different morphologies, planetary curvature by itself probably did not control the morphology of these basins. For comparison, the diameter of the outer ring of the Valhalla basin normalized by the radius of Callisto [Melosh, 1982] is 1.65 . The normalized diameter of the lunar Imbrium basin [Spudis et al., 1988], 0.67, is comparable to that of Hellas, 0.68. Bowl shaped craters having raised rims occur on icy satellites of Satum with normalized diameters of $<0.82$ [Thomas and Squyres, 1988]. A major uncertainty in this comparison is the rheologic response to large impacts of a thin silicate shell compared to a thin icy one. If both types of shells behave similarly, the formation of Martian basins smaller than Chryse (normalized diameter 1.06) may not have been affected by spherical target geometry alone. The morphology of Martian basins probably depends on surface gravity, thermomechanical structure of the lithosphere, and for the largest impacts, planetary curvature.

\section{Basin-Related Resurfacing and Ejecta}

The distribution and geology of basins (Plate 1) indicates that local and regional resurfacing was an important by-product of basin formation. Emplacement of volcanic plains materials and ejecta blankets are both considered here as types of basin related resurfacing processes. For example, many areas of Noachian and Hesperian ridged plains of probable volcanic origin are confined by or associated with multiring basins such as Sirenum, Memnonia-A, Daedalia [Craddock et al., 1990], and Hellas. Volcanism associated with shield and highland patera type calderas occurs along the faulted rugged annuli and outer concentric rings of the Isidis and Hellas basins [e.g., Wichman and Schultz, 1989; Greeley and Crown, 1990]. Volcanic resurfacing of Mars is inferred to have been particularly important volumetrically during Noachian and Early Hesperian times [Tanake et al., 1988; Barlow, 1988; Wichman and Schultz, 1989]. Emplacement of regionally extensive plains units in Lunae Planum and elsewhere [Frey et al., 1988] during Early Hesperian time also appears to have been influenced by impact basin topography and distribution.

Multiring basins probably redeposited large quantities of crustal materials as ejecta. Roth et al. [1989] interpret the shallow depths of large Martian craters as evidence for crater-diameter independent resurfacing of cratered terrain (e.g., basin ejecta, regional plains emplacement), whereas Woronow [1977] has suggested that obliteration of craters is more likely to occur by superposition of 
other craters than by ejecta burial. The amount of material ejected by multiring basins depends in part on the diameter of the transient cavity and the depth of excavation. A comprehensive treatment of scaling relations for multiring basins, diameters and depths of transient and excavation cavities, and their possible dependence on lithospheric structure is beyond the scope of this paper and, indeed, is not yet available in the literature. In lieu of quantitative guidelines, we choose to associate the maximum diameter of the basin transient cavity with the inner diameter of the rugged annulus (e.g., Argyre, Isidis, Hellas) or massif ring (e.g., Orientale [Melosh, 1989], Ladon, Chryse). Two models of transient cavity geometry may give useable extreme values. A model of proportional growth of basin transient cavities in spherical shells favored by Spudis et al. [1988] for the lunar Imbrium basin assumes a ratio of transient cavity diameter $D_{t C}$ to transient cavity depth $d_{t c}$ of about 5 , with the depth of excavation $d_{e x}$ about half this value. In contrast, nonproportional growth models feature ratios of $D_{t c}$ to $d_{t c}$ of 10-20 [see Wichman and Schultz, 1989]. We attempt to bracket possible depths of excavation $d_{e x}$ for Martian basins by choosing $D_{t c} / d_{e x}=10$ (proportional growth) and 40 (nonproportional growth) (Table 3). The inferred depth of excavation for basins between Ladon $(D=975 \mathrm{~km})$ and Chryse $(D$ $=3600 \mathrm{~km}$ ) in size ranges from $\sim 45$ to $135 \mathrm{~km}$ (proportional growth) and $\sim 10$ to $35 \mathrm{~km}$ (nonproportional growth). These crude estimates suggest that Martian multiring basins may have excavated material from substantial depthe and that transient cavity depths may have been comparable to the lithospheric thickness at the time of impact. However, ejecta deposits can be identified only with difficulty for Martian impact basins [Mouginis-Mark et al., 1981; Edgett, 1988; Schultz et al., 1982], perhaps because of the effects of surface volatiles and atmosphere on ejecta emplacement [Schultz, 1988, 1989] and active erosion and deposition on Noachian Mars. Thus the thickness and extent of ejecta from Martian multiring basins remain an open question and an important problem for further research [e.g., MacKinnon and Tanaka, 1989]. Given the number and size of these basins, however, basin ejecta probably forms a sizeable component of Noachian materials.

\section{Basins and Volcanotectonic Provinces}

Two large basins, Elysium and Utopia, influence much of the overall topography and distribution of Noachian and Hesperian materials in the northern plains region. The Borealis basin, if it

TABLE 3. Estimated Depths of Excavation $d_{a x}$ for Selected Martian Basins

\begin{tabular}{cccc}
\hline Basin & $D_{L c}{ }^{a}, \mathbf{k m}$ & $d_{a x}{ }^{b}, \mathbf{k m}$ & $d_{\alpha c^{c}, \mathbf{k m}}$ \\
\hline Chryse & 890 & 89 & 22 \\
Hellas & 1350 & 135 & 34 \\
Isidis & 1100 & 110 & 28 \\
Argyre & 540 & 54 & 14 \\
Ladon & 450 & 45 & 11 \\
\hline
\end{tabular}

\footnotetext{
${ }^{a}$ Maximum diameter of transient cavity $D_{t c}$ interpreted to be $\leq$ the inner diameter of rugged annulus (Hellas, Isidis, Argyre) or massif ring (Chryse, Ladon). 1988].

${ }^{c}$ Assumes nonproportional growth of transient cavity [Wichman and Schultz, 1989].
}

exists, also underlies this region. Thus the fundamental topographic, geologic, and perhaps geophysical dichotomy between the northern lowlands and surrounding highlands appears to have been established before the end of the period of heavy meteoritic bombardment [Frey and Schultz, 1988]. The Elysium volcanic complex [Hall et al., 1986] apparently became localized and grew in the region of overlap between the postulated Elysium and Utopia basins [Frey and Schultz, This issue]. The northern plains are covered by a veneer of material sufficiently thin to obscure, but not completely bury, the underlying multiring topography of the basins. Preservation of basins such as Utopia [McGill, 1989] and continuity of the Isidis and Chryse basins across the dichotomy boundary [Schulzz et al., 1982] indicates that relatively little disruption of the northem plains region has occurred since these basins were created. The contribution of internal processes to the formation of the planetary dichotomy, therefore, was either significant but very early (before Elysium and Utopia basins) or late and relatively minor. These constraints are particularly important in view of revived interest in a thermally active early Mars and concomitant intemal origin for the planetary dichotomy [Schubert et al., 1989; McGill and Dimitriou, 1990].

Tharsis and Elysium appear to be associated with large multiring basins (Plate 1b). Regionally thin, weak lithosphere is commonly cited as a prerequesite to nucleation of Tharsis and growth of its distinctive topography, volcanic pile, and structure [Banerdt et al., 1982; Solomon and Head, 1982; Schubert et al., 1989] and early large impact basins provide a plausible mechanism for producing these initial conditions. Interaction between mantle processes [e.g., Finnerty et al., 1988] and multiring basin structure may account for the localization and growth of Tharsis and Elysium [Frey and Schultz, This issue].

\section{CONCLUSIONS}

Three subclasses of multiring basins are suggested by the systematic variation in basin morphology with increasing size. Multiring basins up to $\sim 1850 \mathrm{~km}$ in diameter are characterized by Orientale type concentric structure and a cumulative frequency power law slope of $\mathbf{- 0 . 7 5}$. Basins larger than Argyre are defined by rugged concentric annuli and a power law slope of nearly $\mathbf{- 2}$. Basins larger than Chryse $(D=3600 \mathrm{~km}$ ) exhibit multiple concentric rings and very shallow topographic profiles. The progressive change in multiring basin morphology with increasing diameter may result from interaction of basin forming impacts with weak, thin lithosphere and, for the largest impacts, spherical target geometry.

Multiring basins are found in all parts of Mars, including the northern lowlands, Tharsis, and surrounding highlands, and impact basins are associated with much of the planet's later volcanic and tectonic activity. The spatial association of major volcanotectonic provinces such as Tharsis and Elysium with large multiring basins suggests that these early impacts contributed to favorable initial conditions for the nucleation and growth of these long-lived complexes. The planetary terrain dichotomy was probably formed during heavy meteoritic bombardment because multiring basins are still preserved in the northern lowlands and across the dichotomy boundary (Isidis). Thus any deformation of northern lowlands by internal processes after its formation was insufficient to destroy these impact basins. Results from the revised basin record confirm that relative crater densities among the terrestrial planets appear to be comparable. 
More basins are presently identified in the western hemisphere of Mars than anywhere else on the planet and this might reflect geologic reactivation of certain basins rather than a nonrandom geographic distribution. The extensive expanses of Noachian and Hesperian materials mapped in the eastern and southern hemispheres are good places to search for additional basins. The formation and emplacement of ejecta materials associated with Martian multiring basins is an important unsolved problem. Mapping of Noachian materials should focus at least in part on identifying basin ejecta and quantifying its thickness and distribution. Theoretical analysis of impact into thin, rheologically layered spherical targets is necessary to predict the volume and distribution of ejecta deposited on the surface. Additional work is needed to more thoroughly characterize basin related structures and to test the validity of recently proposed basins.

Acknowledgments. Thoughtful suggestions by Bill McKinnon and an anonymous reviewer improved the manuscript. We thank George McGill, Steven Squyres, and Don Wilhelms for comments during the past year that increased our understanding of basin statistics. Nadine Barlow kindly provided crater data for the Moon and Mars. We thank Bob Craddock for a preprint of his work on the Daedalia basin, Rob Wichman and Bob Strom for helpful discussions, and Maria Zuber for comments on the manuscript. The $R$ plots in Figure 6 were motivated by Bill Hartmann's question at the MEVTV Workshop on Early Mars in Easton, Maryland, on the relationship between large basin and crater populations on Mars. Computer ploting of basin rings was graciously done by Susan Tokarsik. This work was supported by the Mars Data Analysis Program "Mars: Evolution of Volcanism, Tectonism, and Volatiles" (MEVTV) of the NASA Solar System Exploration Division. R.A.S. was supported by a Resident Research Associateship at NASA Goddard Space Flight Center through the National Academy of Sciences/National Research Council.

\section{REFERENCES}

Baer, G., and Z. Reches, Doming mechanisms and structural development of two domes in Ramon, southem Israel, Tectonophysics, 166, 293$315,1989$.

Banerdt, W.B., R.J. Phillips, N.H. Sleep, and R.S. Saunders, Thick shell tectonics on one-plate planets: Applications to Mars, J. Geophys. Res., 87, 9723-9733, 1982.

Banerdt, W.B., M.P. Golombek, and K.L. Tanaka, Stress and tectonics on Mars, in Mars, edited by H.H. Kieffer et al., University of Arizona Press, Tucson, in press, 1990.

Barlow, N.G., Crater size-frequency distributions and a revised Martian relative chronology, Icarus, 75, 285-305, 1988.

Barlow, N.G., Constraints on early events in Martian history derived from the cratering record, J. Geophys. Res., in press, 1990.

Benz, W., A.G.W. Cameron, and HJ. Melosh, The origin of the Moon and the single-impact hypothesis II, Icarus, 81, 113-131, 1989.

Bevington, P.R., Data Reduction and Error Analysis for the Physical Sciences, 336 pp., McGraw-Hill, New York, 1969.

Carr, M.H., Recharge of the early atmosphere of Mars by impact-induced release of $\mathrm{CO}_{2}$, Icarus, 79, 311-327, 1989.

Chapman, C.R., and W.B. McKinnon, Cratering of planetary satellites, in Satellites, edited by J.A. Bums and M.S. Matthews, Pp. 492-580, University of Arizona Press, Tucson, 1986.

Chicarro, A.F., P.H. Schultz, and P. Masson, Global and regional ridge pattems on Mars, Icarus, 63, 153-174, 1985.

Comer, R.P., S.C. Solomon, and J.W. Head, Mars: Thickness of the lithosphere from the tectonic response to volcanic loads, Rev. Geophys., 23, 61-92, 1985.

Craddock, R.A., R. Greeley, and P.R. Christensen, Evidence for an ancient impact basin in Daedalia Planum, Mars, J. Geophys. Res., in press, 1990.

Crater Analysis Techniques Working Group, Standard techniques for presentation and analysis of crater size-frequency data, Icarks, 37, 467474, 1979.

Croft, S.K., The modification stage of basin formation: Conditions of ring formation, Multi-ring Basins, edited by P.H. Schultz and R.B. Merrill, Proc. Lunar Planet. Sci., 12A, 277-257, 1981.
Edgett, K.S., Ejecta deposits of large Martian impact basins: A useful geologic tool and window to early Martian history? paper presented at MEVTV-LPI Workshop: Early Tectonic and Volcanic Evolution of Mars, Easton, Md., 1988.

Finnerty, A.A., R.J. Phillips, and W.B. Banerdt, Igneous processes and closed system evolution of the Tharsis region of Mars, J. Geophys. Res., 93, 10,225-10,235, 1988.

Frey, H.V., and R.A. Schultz, Large impact basins and the mega-impact origin for the crustal dichotomy on Mars, Geophys. Res. Lett., 15, 229 232, 1988.

Frey, H.V., and R.A. Schultz, Overlapping impact basins and the origin of the Martian crustal dichotomy, Elysium, and Tharsis, paper presented at Fourth Intemational Conference on Mars, NASA, Tucson, Ariz., 1989.

Frey, H.V., and R.A. Schultz, Speculations on the origin and evolution of the Utopia-Elysium lowlands of Mars, J. Geophys. Res., this issue.

Frey, H.V., R.A. Schultz, and T.A. Maxwell, The Martian crustal dichotomy: Product of accretion and not a specific event? (abstract), Lunar Planet. Sci., XVII, 241-242, 1986.

Frey, H.V., A.M. Semeniuk, J.A. Semeniuk, and S. Tokarsik, A widespread common age resurfacing event in the highland-lowland transition zone in eastem Mars, Proc. Lunar Planet. Sci. Conf., 18th, 679-699, 1988.

Greeley, R., Planetary Landscapes, 265 pp., Allen Unwin, Winchester, Mass., 1985.

Greeley, R., and D.A. Crown, Volcanic geology of Tymhena Patera, Mars, J. Geophys. Res., 95, 7133-7149, 1990.

Greeley, R., and J.E. Guest, Geologic map of the eastem equatorial region of Mars, scale 1:15,000,000, U.S. Geol. Surv. Misc. Invest. Ser. Map, I-1802-B, 1987.

Grizzaffi, P., and P.H. Schultz, Isidis basin: Site of an ancient volatile-rich debris layer, Icarks, 77, 358-381, 1989.

Gumis, M., Martian cratering revisited: Implications for early geologic evolution, Icarus, 48, 62-75, 1981.

Hall, J.L., S.C. Solomon, and J.W. Head, Elysium region, Mars: Tests of lithospheric loading models for the formation of tectonic features, $J$. Geophys. Res., 91, 11,377-11,392, 1986.

Hartmann, W.K., and S.M. Vail, Giant impactors: Plausible sizes and populations, in Origin of the Moon, edited by W.K. Hartmann, R.J. Phillips, and G.J. Taylor, pp. 551-566, Lunar and Planetary Institute, Houston, Tex., 1986.

Head, J.W., Orientale multiringed basin interior and implications for the petrogenesis of lunar highland samples, Moon, 11, 327-356, 1974.

Hodges, C.A., Geologic map of the Argyre quadrangle of Mars, scale 1:5,000,000, U.S. Geol. Surv. Misc. Invest. Ser. Map, I-1181, 1980.

Howard, K.A., Fresh lunar impact craters: Review of variation with size, Proc. Lunar Planet. Sci. Conf., 5th, 61-69, 1974.

Malin, M.C., Comparison of large crater and multi-ringed basin populations on Mars, Mercury, and the Moon, Proc. Lunar Sci. Conf., 7th, 3589. $3602,1976$.

MacKinnon, D.J., and K.L. Tanaka, The impacted Martian crust: Structure, hydrology, and some geologic implications, J. Geophys. Res., 94, 17,359-17,370, 1989.

McCauley, J.F., Orientale and Caloris, Phys. Earth Planet. Inter., 15, 220 250, 1977.

McGill, G.E., Buried topography of Utopia, Mars: Persistence of a giant impact depression, J. Geophys. Res., 94, 2753-2759, 1989.

McGill, G.E., and A.M. Dimitriou, Origin of the Martian global dichotomy by crustal thinning in the late Noachian or early Hesperian, J. Geophys. Res., in press, 1990.

McKinnon, W.B., Application of ring tectonic theory to Mercury and other solar system bodies, Multi-ring Basins, edited by P.H. Schultz and R.B. Merrill, Proc. Lunar Planet. Sci., 12A, 259-273, 1981.

McKinnon, W.B., and H.J. Melosh, Evolution of planetary lithospheres: Evidence from multiringed structures on Ganymede and Callisto, Icarus, 44, 454-471, 1980.

Melosh, H.J., A simple mechanical model of Valhalla basin, Callisto, $J$. Geophys. Res., 87, 1880-1890, 1982.

Melosh, H.J., Impact Cratering: A Geologic Process, 245 pp., Oxford University Press, New York, 1989.

Melosh, H.J., and W.B. McKinnon, The mechanics of ringed basin formation, Geophys. Res. Lett., 5, 985-988, 1978.

Moore, H.J., C.A. Hodges, and D.H. Scott, Multi-ringed basinsIllustrated by Orientale and associated features, Proc. Lunar Sci. Conf., Sth, 71-100, 1974. 
Mouginis-Mark, P.J., V.L. Sharpton, and B.R. Hawke, Schiaparelli basin, Mars: Morphology, tectonics, and infilling history, Multi-ring Basins, edited by P.H. Schultz and R.B. Merrill, Proc. Lunar Planet. Sci., 12A, 155-172, 1981.

Phillips, R.J., N.H. Sleep, and W.B. Banerdt, Permanent uplift in magmatic systems with application to the Tharsis region of Mars, $J$. Geophys. Res., 95, 5089-5100, 1990.

Pike, R.J., and P.D. Spudis, Basin-ring spacing on the Moon, Mercury, and Mars, Earth Moon Planets, 39, 129-194, 1987.

Roth, L.E., G.S. Downs, R.S. Saunders, and G. Schubert, Radar altimetry of south Tharsis, Mars, Icarus, 42, 287-316, 1980.

Roth, L.E., R.S. Saunders, G.S. Downs, and G. Schubert, Radar altimetry of large Martian craters, Icarus, 79, 289-310, 1989.

Ryder, G., Lunar samples, lunar accretion and the early bombardment of the Moon, Eos Trans. AGU, 71, 313-323, 1990.

Schubert, G., D.L. Turcotte, S.C. Solomon, N. Sleep, and M. Drake, Origin and thermal evolution of Mars, paper presented at Fourth International Conference on Mars, NASA, Tucson, Ariz., 1989.

Schultz, P.H., Evolution of intermediate-age impact basins on the Moon, paper presented at Conference on the Lunar Highlands Crust, Lunar and Planetary Institute, Houston, Tex., 1979.

Schultz, P.H., Impact basin control of volcanic and tectonic provinces on Mars (abstract), Lunar Planet. Sci., XV, 728-729, 1984.

Schultz, P.H., Cratering on Mercury: A relook, in Mercury, edited by F. Vilas, C.R. Chapman, and M.S. Matthews, University of Arizona Press, Tucson, pp. 274-335, 1988.

Schultz, P.H., Factors controlling impact ejecta emplacement on Mars, paper presented at Fourth Intemational Conference on Mars, NASA, Tucson, Ariz., 1989.

Schultz, P.H., and H. Glicken, Impact crater and basin control of igneous processes on Mars, J. Geophys. Res., 84, 8033-8047, 1979.

Schultz, P.H., R.A. Schultz, and J. Rogers, The structure and evolution of ancient impact basins on Mars, J. Geophys. Res., 87, 9803-9820, 1982.

Schultz, R.A., Assessment of global and regional tectonic models for faulting in the ancient terrains of Mars, J. Geophys. Res., 90, 78497860, 1985. (Correction, J. Geophys. Res., 91, 12,861-12,863, 1986.)

Schultz, R.A., Possible deficiency of large Martian craters and relative cratering of the terrestrial planets (abstract), Lunar Planet. Sci., XXI, 1107-1108, 1990.

Scott, D.H., and K.L. Tanaka, Mars Tharsis region: Volcanotectonic events in the stratigraphic record, Proc. Lunar Planet. Sci., 1lth, 2403$2421,1980$.

Scott, D.H., and K.L. Tanaka, Geologic map of the western equatorial region of Mars, scale 1:15,000,000, U.S. Geol. Surv. Misc. Invest. Ser. Map, I-1802-A, 1986.

Sjogren, W.L., Mars gravity: High-resolution results from Viking Orbiter 2, Science, 203, 1006-1010, 1979.

Sjogren, W.L., and R.N. Wimberley, Mars: Hellas Planitia gravity analysis, Icorus, 45, 331-338, 1981.

Smith, B.A., and the Voyager Imaging Team, The Jupiter system through the eyes of Voyager 1, Science, 204, 951-972, 1979.

Solomon, S.C., and J.W. Head, Lunar mascon basins: Lava filling, tectonics, and evolution of the lithosphere, Rev. Geophys., 18, 107-141, 1980.

Solomon, S.C., and J.W. Head, Evolution of the Tharsis Province of Mars: The importance of heterogeneous lithospheric thickness and volcanic construction, J. Geophys. Res., 87, 9755-9774, 1982.

Solomon, S.C., W.L. Sjogren, and S.R. Bratt, The structure of the Isidis basin, Mars, from gravity anomalies (abstract), Lunar Planet. Sci., XIV, 725-726, 1983.

Spudis, P.D., B.R. Hawke, and P.G. Lucey, Materials and formation of the Imbrium basin, Proc. Lunar Planet. Sci. Conf., 18th, 155-168, 1988.

Squyres, S.W., The distribution of lobate debris aprons and similar flows on Mars, J. Geophys. Res., 84, 8087-8096, 1979.

Stam, M., Morphology of Martian impact basins: Modification styles and tectonic setting, M.S. thesis, Univ. of Mass., Amherst, 1984.

Stam, M., Newly discovered Martian impact basins (abstract), Lunar Planet. Sci., XVI, 813-814, 1985.
Strom, R.G., Origin and relative age of lunar and mercurian intercrater plains, Phys. Earth Planet. Inter., 15, 156-172, 1977.

Strom, R.G., The solar system cratering record: Voyager 2 results at Uranus and implications for the origin of impacting objects, Icarus, 70 , 517-535, 1987.

Strom, R.G., and G. Neukum, The cratering record on Mercury and the origin of impacting objects, in Mercury, edited by F. Vilas, C.R. Chapman, and M.S. Matthews, University of Arizona Press, Tucson, pp. 336-373, 1988.

Strom, R.G., S.K. Croft, and N.G. Barlow, The Martian impact cratering record, in Mars, edited by H.H. Kieffer et al., University of Arizona Press, Tucson, in press, 1990.

Suppe, J., Principles of Structural Geology, 537 pp., Prentice-Hall, Englewood Cliffs, NJ., 1985.

Tanaka, K.L., and P.A. Davis, Tectonic history of the Syria Planum Province of Mars, J. Geophys. Res., 93, 14,893-14,917, 1988.

Tanaka, K.L., and D.H. Scot, Geologic map of the polar regions of Mars, scale 1:15,000,000, U.S. Geol. Surv., Misc. Invest. Ser., Map I-1802C. 1987.

Tanaka, K.L., N.K. Isbell, D.H. Scott, R. Greeley, and J.E. Guest, The resurfacing history of Mars: A synthesis of digitized, Viking-based geology, Proc. Lunar Planet. Sci. Conf., 18th, 665-678, 1988.

Thomas, P.J., and S.W. Squyres, Relaxation of impact basins on icy satellites, J. Geophys. Res., 93, 14,919-14,932, 1988.

U.S. Geological Survey, Topographic maps of the westem, eastem equatorial and polar regions of Mars, scale 1:15,000,000, U.S. Geol. Surv. Misc. Invest. Ser. Map, I-2030, 1989.

Watters, T.R., and T.A. Maxwell, Orientation, relative age, and extent of the Tharsis plateau ridge system, J. Geophys. Res., 91, 8113-8125, 1986.

Wetherill, G.W., Evolution of the Earth's planetesimal swarm subsequent to the formation of the Earth and Moon, Proc. Lunar Sci. Conf., 8th, 1$16,1977$.

Wetherill, G.W., Nature and origin of basin-forming projectiles, Multi-ring Basins, edited by P.H. Schultz and R.B. Merrill, Proc. Lunar Planet. Sci., 12A, 1-18, 1981.

Wichman, R.W., and P.H. Schultz, Sequence and mechanisms of deformation around the Hellas and Isidis impact basins on Mars, $J$. Geophys. Res., 94, 17,333-17,357, 1989.

Wilhelms, D.E., Comparison of Martian and lunar multi-ringed circular basins, J. Geophys. Res., 78, 4084-4095, 1973.

Wilhelms, D.E., The geologic history of the Moon, US. Geol. Surv. Prof. Pap., 1348, 302 pp., 1987.

Wilhelms, D.E., and S.W. Squyres, The Martian hemispheric dichotomy may be due to a giant impact, Nature, 309, 138-140, 1984.

Wood, C.A., Martian double ring basins: New observations, Proc. Luner Planet. Sci. Conf., 11th, 2221-2241, 1980.

Wood, C.A., and J.W. Head, Comparison of impact basins on Mercury, Mars, and the Moon, Proc. Lunar Sci. Conf., 7th, 3629-3651, 1976.

Woronow, A., Crater saturation and equilibrium: A Monte Carlo simulation, J. Geophys. Res., 82, 2447-2456, 1977.

Woronow, A., A general cratering-history model and its implications for the lunar highlands, Icarus, 34, 76-88, 1978.

Wu, S.S.C., R. Jordan, and F.J. Schafer, Mars global topographic map: 1:15,000,000 scale (abstract), Reports of Planetary Geology and Geophysics Program 1985, NASA Tech. Memo., TM-88383, 614-617, 1986.

H.V. Frey, Geodynamics Branch, Code 921, NASA Goddard Space Flight Center, Greenbelt, MD 20771.

R.A. Schultz, Mackay School of Mines, University of Nevada-Reno, Reno, NV 89557.

(Received July 7, 1989;

revised April 9, 1990;

accepted April 16, 1990) 